\title{
Isolating the Observed Influence of Vegetation Variability on the Climate of La Plata River Basin $\mathscr{O}$
}

\author{
DivyAnsh CHUG AND FRANCINA DOMINGUEZ \\ Department of Atmospheric Sciences, University of Illinois at Urbana-Champaign, Urbana, Illinois
}

(Manuscript received 9 October 2018, in final form 27 April 2019)

\begin{abstract}
This work aims to isolate and quantify the local and remote biogeophysical influences of slowly varying vegetation variability on the climate of La Plata basin (LPB) in the austral spring season (SeptemberNovember) using observational records. Past studies have shown strong land-atmosphere coupling in LPB during this season. The analysis uses a 34-yr record (1981-2014) of the modified enhanced vegetation index (EVI2) from the NASA Making Earth System Data Records for Use in Research Environments (MEaSUREs) Vegetation Index and Phenology dataset and the third-generation normalized difference vegetation index (NDVI) from Global Inventory Modeling and Mapping Studies. The dominant patterns of vegetation index variability in space and time are assessed using empirical orthogonal function/principal component analysis over the LPB. The dominant mode in the austral spring is a vegetation dipole, with greening (browning) or positive (negative) vegetation index anomalies in the northeastern (southwestern) part of the basin. Using the stepwise generalized equilibrium feedback assessment (SGEFA), the effect of the vegetation variability on the atmosphere is then isolated. The dominant mode of LPB vegetation variability in austral spring is related to warmer temperatures in the southwest LPB and enhanced precipitation over the central and southern parts of the basin. A mechanism is proposed for the increase in latent heat flux and cooler temperatures in the northeastern LPB due to greening, and the increase in sensible heat flux, warmer temperatures, and decrease in surface pressure in southwestern LPB due to browning. The geostrophic response to this induced pressure gradient leads to anomalous northerly enhancement of moisture-laden winds, deeper penetration of moisture into LPB, and increased precipitation over the central and southern parts of the basin.
\end{abstract}

\section{Introduction}

Changes in the land surface, specifically vegetation, can modulate climate at different spatiotemporal scales (e.g., Bonan 1997; Dickinson and Henderson-Seller 1988; Bounoua et al. 2000). The atmosphere, through variations in precipitation, temperature, wind, $\mathrm{CO}_{2}$ concentration, and radiation, dominates this complex two-way interaction (Budyko 1974; Woodward, 1987; Nemani et al. 2003; Woodward et al. 2004). As a response, the vegetation exerts a feedback on the atmosphere by modulating the exchanges of energy, moisture, and momentum (biogeophysical feedbacks) and chemical composition (biogeochemical feedbacks) (Pielke et al. 1998; Bonan 2002).

Supplemental information related to this paper is available at the Journals Online website: https://doi.org/10.1175/ JCLI-D-18-0677.s1.

Corresponding author: Francina Dominguez, francina@ illinois.edu
Changes in vegetation modify the properties of the land surface albedo, roughness length, root depth, stomatal resistance, and so on. This has a direct effect on both biogeophysical and biogeochemical interactions, the local boundary layer, and eventually the processes that control hydroclimate (Stohlgren et al. 1998; Pielke et al. 2007).

The spatiotemporal heterogeneity of terrestrial vegetation results in land-atmosphere interactions across multiple scales, making it difficult to completely observe and understand (Santanello et al. 2018). Numerical modeling studies to assess global-scale coupling relationships have been a major focus of the climate community (Santanello et al. 2018). One of the most notable efforts, the Global Land Atmosphere Coupling Experiment (GLACE; Koster et al. 2004, 2006; Guo et al. 2006), highlighted regions of strong coupling in global circulation models where antecedent soil moisture had significant influence on precipitation.

This study analyzes land-atmosphere interactions over the South American continent, in particular over the La Plata River basin (LPB) using observations. The 


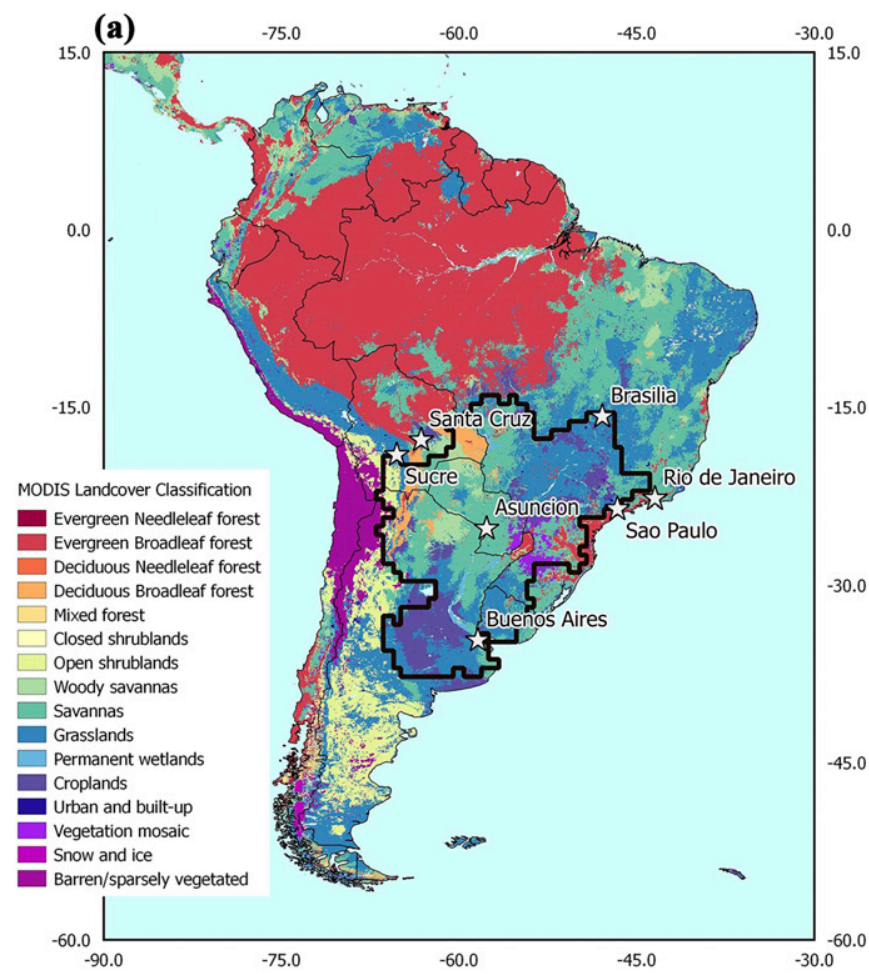

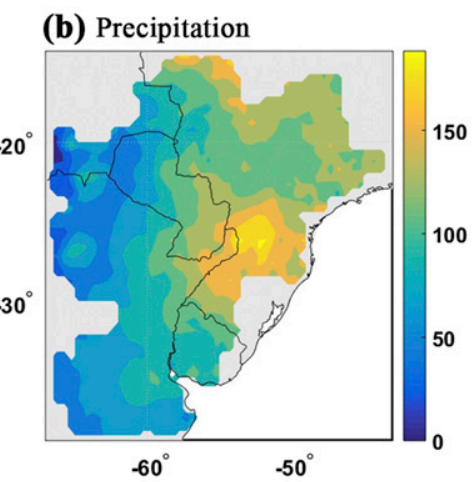

(c) Enhanced vegetation index

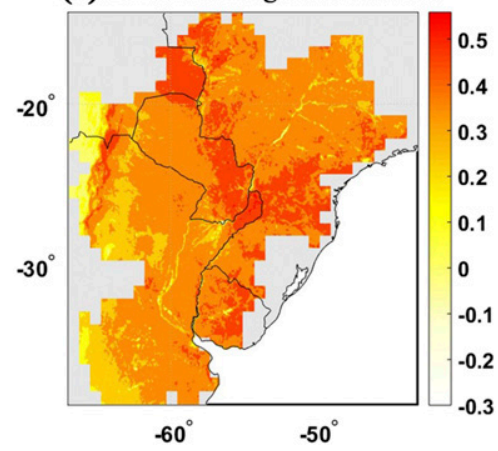

FIG. 1. (a) Remotely sensed land cover type from the MODIS dataset provided by the Global Land Cover Facility. The black line indicates the boundary of LPB. Markers indicate important cities located in and around LPB. Terrestrial water bodies are masked with the same color as the ocean. Also shown are monthly (b) precipitation (mm month ${ }^{-1}$ ) and (c) modified enhanced vegetation index (unitless), across LPB averaged for the period 1981-2014. Precipitation data are obtained from the University of Delaware dataset and modified enhanced vegetation index from the NASA MEaSUREs Vegetation Index and Phenology dataset.

LPB $\left(14^{\circ}-38^{\circ} \mathrm{S}, 43^{\circ}-67^{\circ} \mathrm{W}\right.$; Fig. 1a) is widely recognized as a land-atmosphere coupling hotspot, where changes in land surface can alter the atmospheric state and modulate processes that control hydroclimate (Sörensson and Menéndez 2011; Ruscica et al. 2015; Spennemann et al. 2018). The basin stretches over five countries: Argentina, Bolivia, Brazil, Paraguay, and Uruguay (Fig. 1a). LPB is home to approximately 160 million inhabitants, or roughly $60 \%$ of the population of the five countries (FAO 2016). It is the second largest basin of South America after the Amazon. From an economic perspective, this region far exceeds the well-studied Amazon basin in hydroelectric power, agriculture, and livestock, and supports $70 \%$ of the combined gross domestic product of these five nations (Barros et al. 2006; Flinker 2012). Most importantly, LPB is one of the largest food and crop producing regions globally (FAO 2016). The austral spring season [September-November (SON)] is the agricultural growing season for the summer crop. Agriculture in the basin is dominated by soybean, maize, rice, sunflower, and sugarcane. Most of the cultivation is rain-fed. By 2003, the extent of irrigation was limited to only $4.6 \%$ of the potentially agricultural land (Barros et al. 2006).

Figures $1 \mathrm{~b}$ and $1 \mathrm{c}$ show the climatological monthly precipitation and modified enhanced vegetation index respectively, averaged over the period 1981-2014. The dominant driver of precipitation in the northern part of the basin is the South American monsoon system (Caffera and Berbery 2002; Marengo et al. 2012). The semipermanent South American low-level jet (SALLJ; Marengo et al. 2004; Vera et al. 2006) also plays a critical role in the regional climate by transporting moisture from the tropics and subtropics to higher latitudes, and through its strong relationship to precipitation in the basin (Salio et al. 2002; Vera et al. 2006). The SALLJ's role in the South American climate, particularly in the warm season, and its impact on the hydrological cycle of LPB have been extensively studied in the past (Rasmusson and Mo 1996; Nogués-Paegle and Mo 1997; Salio et al. 2002; Nicolini et al. 2002; Marengo et al. 2004; Liebmann et al. 2004). The SALLJ exhibits enhanced precipitation at the exit area and a highly variable meridional extent. A deeper penetration of the SALLJ 
toward high latitudes is associated with the deepening of a thermal-orographic low pressure system located east of the Andes around $28^{\circ} \mathrm{S}$ known as the northwestern Argentinian low (NAL; Seluchi et al. 2003). The NAL aids in the deeper meridional penetration of SALLJ, which leads to enhanced precipitation over northern Argentina since the exit region of the jet is shifted southward (Salio et al. 2002; Saulo et al. 2010). Such events of a northerly enhanced SALLJ are termed Chaco jet events (Salio et al. 2002). An interesting aspect of the NAL is that it is highly sensitive to changes on the surface that alter the surface energy budget (Seluchi et al. 2003; Ferreira et al. 2006).

Land-atmosphere interactions are important drivers of climate in the LPB. Modeled estimates show that between $60 \%$ and $70 \%$ of the moisture that falls as mean annual precipitation over the LPB originates over terrestrial sources (Dirmeyer and Brubaker 2007; Zemp et al. 2014; Martinez and Dominguez 2014), including $24 \%$ from the basin itself and $20 \%$ from the southern Amazon. The southern LPB has been found to be a hotspot of both soil moisture-evapotranspiration and soil moisture-precipitation coupling (Sörensson and Menéndez 2011) based on quantification of coupling strength (Koster et al. 2004) from experiments using a regional climate model. Using a similar methodology, Ruscica et al. (2015) concluded that LPB exhibits a strong feedback between soil moisture and precipitation through evapotranspiration, and this coupling is enhanced under drier soil moisture conditions. Other studies using different coupling metrics and datasets have also confirmed the presence of this hotspot (e.g., Spennemann and Saulo 2015). Due to the importance of the land surface-atmosphere feedbacks, the atmospheric response in the region is highly sensitive to soil moisture initialization, and is also a function of vegetation types (Sörensson and Berbery 2015). Lee and Berbery (2012) performed numerical simulations to find that replacement of the forests and savanna to crops causes decreased moisture convergence and precipitation in the northern part of the basin (through albedo and roughness feedbacks) and increased convergence and precipitation to the south (mainly through albedo feedback). This also demonstrates that the hydroclimatic response to sub-basin-scale changes in the LPB varies depending on the region. Compared to modeled estimates of land-atmosphere coupling, studies using observed data have been rare. Notably, Spennemann et al. (2018) performed independent estimations of land-atmosphere interaction in LPB using remotely sensed data as well as coupled and uncoupled model output. They observed a larger spatial extent and intensified coupling during anomalously dry events as compared to wet events, consistent in all datasets as well as with previous studies (e.g., Ruscica et al. 2015).

The current understanding of the role of land surface in modulating the climate of the LPB has been largely derived from numerical modeling studies [with Spennemann et al. (2018) being a notable exception]. However, several key limitations exist in the assessment of feedbacks using numerical models. While different models differ in their ability to represent the physical mechanisms that are responsible for changes in the system, the results also vary depending on the dynamical cores, physics, parameterizations, and resolution (Wang et al. 2014; Yu et al. 2017b). The sensitivity experiments usually employed (e.g., complete or partial deforestation, or replacing a land cover type with another land cover type, etc.) fail to capture realistic changes in vegetation. The varied spatiotemporal scales across different studies tend to confound community thinking and consensus building (Guillod et al. 2015; Knist et al. 2016). Additionally, untangling the physical mechanisms responsible for the changes at the land-atmosphere interface is not straightforward, and standard model outputs are often insufficient to diagnose coupled sensitivities.

Another challenge facing studies of land-atmosphere interactions is distinguishing the response of the atmosphere to changes in the surface variables from the large atmospheric internal noise, and its isolation from the impact of other potential forcings [e.g., sea surface temperatures (SSTs)]. The use of statistical techniques that can incorporate spatiotemporal variability, like Granger causality (Granger 1969) and equilibrium feedback assessment (EFA; Frankignoul et al. 1998), limits the analysis to local feedback, and may not remove the impact of other forcings. The generalized equilibrium feedback assessment (GEFA; Liu et al. 2008; Liu and Wen 2008) and the stepwise GEFA (SGEFA; Yu et al. 2017a) overcome some of the aforementioned challenges. The GEFA framework was developed to isolate the local and remote feedbacks of a single forcing in the presence of other forcings. GEFA's ability to isolate the oceanic and terrestrial feedbacks on the North American climate has previously been demonstrated with observations as well as model experiments (Wang et al. 2013, 2014). SGEFA is a modification and an improvement over GEFA through elimination of statistically unimportant forcings, thereby reducing the error in the GEFA feedback (Yu et al. 2017a). SGEFA has been reliably employed and validated against GEFA as well as dynamical assessments for the North African climate ( $\mathrm{Yu}$ et al. 2017a,b; Wang et al. 2017). Given the capability of GEFA and SGEFA in isolating the local and remote impact of vegetation, it is a valuable tool for the current analysis. 
The purpose of this study is to quantify and isolate the observed influence of interannual variability of monthly vegetation indices on the seasonal climate across LPB in the austral spring season (SON). The spring season was chosen based on past modeling studies that suggest strong links between the land surface and atmospheric variability (Lee and Berbery 2012; Ruscica et al. 2015), when evapotranspiration is strongly sensitive to moisture over a land surface recovering from the dry season. Moreover, as the agricultural growing season, the spring months have crucial importance in terms of the interannual variability of precipitation. This work involves the identification of the dominant forcings affecting the LPB climate, and obtaining the feedbacks of the vegetation after excluding the feedback of SST variability. For LPB, this represents a first attempt at assessing the regional atmospheric response to the vegetation variability using observational data, and a step toward narrowing down the mechanisms involved.

\section{Data and methodology}

\section{a. Data}

The vegetation forcing in this study is represented by monthly-mean remotely sensed vegetation indices (VIs) from two different datasets. This allows for a more robust estimation of the vegetation feedback by reducing the sensor dependence of the results. The first dataset is the normalized difference vegetation index (NDVI; Pinzon et al. 2005; Tucker et al. 2005) from Global Inventory Modeling and Mapping Studies (GIMMS). The GIMMS NDVI is generated from the Advanced Very High Resolution Radiometer (AVHRR) sensor and is available from July 1981 onward. The second VI dataset is the two-band enhanced vegetation index (EVI2; Jiang et al. 2008; Didan and Barreto 2016) from the NASA Making Earth System Data Records for Use in Research Environments (MEaSUREs) Vegetation Index and Phenology (VIP) dataset. EVI2 is computed using reflectance information from the red and the nearinfrared bands of the Moderate-Resolution Imaging Spectroradiometer (MODIS). It was designed to be compatible with the enhanced vegetation index (EVI) from newer MODIS datasets (Jiang et al. 2008) through backward extension to the AVHRR data record. This dataset, referred to as VIP EVI, is available for the duration of 1981-2014. Together these products provide the longest continuous record of satellite-based terrestrial vegetation indices.

When identifying a dominant mode of vegetation variability, it is possible to erroneously select a mode that is sensor dependent; that is, it could be a manifestation of the limitations of the AVHRR sensor in the overlap period (1981-99). Hence, we also employ the enhanced vegetation index (Running et al. 1994; Huete et al. 2002) from the Collection-6 MODIS dataset (Didan 2015) as a benchmark for validating the identified dominant vegetation forcing from the longer-term datasets. MODIS Collection-6 EVI (referred to herein as MOD6 EVI) is available from 2000 to 2017. For computational efficiency, data for LPB from all VI datasets were remapped to a $0.5^{\circ} \times 0.5^{\circ}$ grid before further analysis.

Monthly SSTs from the Hadley Center Sea Ice and Sea Surface Temperature dataset (HadISST; Rayner et al. 2003) were used to represent the oceanic forcing. Observed air temperature and precipitation for terrestrial South America were extracted from the University of Delaware (UDEL; Willmott and Matsuura 1995) and the University of East Anglia Climate Research Unit (CRU; Mitchell and Jones 2005) datasets. These represent the best available long-term gridded datasets for precipitation and temperature in a region with sparse observational network such as South America. Both datasets are available as monthly mean values since 1901 at a resolution of $0.5^{\circ}$. Geopotential height, wind, vertical integral of moisture flux (VIMF), surface heat fluxes (latent and sensible), boundary layer depth, and mean sea level pressure (MSLP) were downloaded from the European Centre for Medium-Range Weather Forecast (ECMWF) interim reanalysis (ERA-Interim; Dee et al. 2011) dataset at a resolution of $0.75^{\circ}$. Despite the shortcoming that ERA-Interim variables do not account for the interannual variability of vegetation properties, we rely on its advanced data assimilation capability to constrain model estimates close to observations. Heights, winds, and VIMF were analyzed for a larger domain centered at South America $\left(160^{\circ} \mathrm{W}-40^{\circ} \mathrm{E}\right.$, $\left.15^{\circ} \mathrm{N}-60^{\circ} \mathrm{S}\right)$. For total terrestrial evaporation, we used the Global Land Evaporation Amsterdam model dataset (GLEAM; Miralles et al. 2011; Martens et al. 2017).

The length of the feedback analysis is limited to the years 1981-2014. Seasonal cycles were removed from all datasets to compute the anomaly field.

\section{b. Methods}

\section{1) EMPIRICAL ORTHOGONAL FUNCTION ANALYSIS}

We use empirical orthogonal function (EOF) analysis (Obukhov 1947, 1960; Fukuoka 1951; Lorenz 1956; Kutzbach 1967; Preisendorfer 1988; Bretherton et al. 1992; Hannachi et al. 2007) to decompose the spatiotemporal datasets of the forcing fields of interest to our study (SSTs and vegetation indices) into structures that explain the maximum amount of variance. The analysis 
produces a set of patterns in the spatial dimension called EOFs and a complementary set of series in the time dimension known as principal components (PCs).

For the oceanic forcing, the global ocean north of $60^{\circ} \mathrm{S}$ is divided into seven nonoverlapping basins: the North Atlantic Ocean $\left(\mathrm{NA} ; 20^{\circ}-50^{\circ} \mathrm{N}, 100^{\circ} \mathrm{W}-20^{\circ} \mathrm{E}\right)$, tropical Atlantic Ocean $\left(\mathrm{TA} ; 20^{\circ} \mathrm{S}-20^{\circ} \mathrm{N}, 65^{\circ} \mathrm{W}-15^{\circ} \mathrm{E}\right)$, South Atlantic Ocean $\left(\mathrm{SA} ; 20^{\circ}-60^{\circ} \mathrm{S}, 70^{\circ} \mathrm{W}-20^{\circ} \mathrm{E}\right)$, Indian Ocean (I; $20^{\circ} \mathrm{S}-20^{\circ} \mathrm{N}, 35^{\circ}-120^{\circ} \mathrm{E}$ ), North Pacific Ocean (NP; $20^{\circ}-50^{\circ} \mathrm{N}, 120^{\circ} \mathrm{E}-100^{\circ} \mathrm{W}$ ), tropical Pacific Ocean (TP; $20^{\circ} \mathrm{S}-20^{\circ} \mathrm{N}, 120^{\circ} \mathrm{E}-60^{\circ} \mathrm{W}$ ), and South Pacific Ocean (SP; $20^{\circ}-60^{\circ} \mathrm{S}, 120^{\circ} \mathrm{E}-70^{\circ} \mathrm{W}$ ). For the terrestrial forcing, vegetation index anomalies for the region encompassed by LPB $\left(14^{\circ}-38^{\circ} \mathrm{S}, 43^{\circ}-67^{\circ} \mathrm{W}\right)$ were extracted and remapped to a $0.5^{\circ} \times 0.5^{\circ}$ grid. EOF analysis is performed over the months of August-November (ASON) to extract the leading two modes from each ocean basin and one dominant mode from the terrestrial basin for each month. The PCs serve as reduced dimension forcings for the feedback analysis.

Some studies using GEFA and SGEFA have employed the time series of area-averaged vegetation index anomalies as the land surface forcing (e.g., Wang et al. 2014). We use the EOF analysis instead to effectively represent the differential behavior of vegetation greenness in the northern and southern parts of this large basin, using a single forcing. Moreover, we use one mode of vegetation index variability to represent a land surface forcing for the LPB climate. This does not imply that all of the land surface feedback is driven by vegetation greenness. Ideally, we would have long-term observations of soil moisture (throughout the root zone) but currently these remotely sensed observations are not available throughout the root zone, and surface soil moisture observations are not available for the required duration of analysis. Vegetation index variability has been used as a proxy to assess the combined influence of all sources of land surface variability as captured by the vegetation greenness (as the vegetation index indirectly includes the effect of soil moisture, surface roughness, etc.).

\section{2) Generalized Equilibrium FeEdBACK ASSESSMENT FRAMEWORK (GEFA AND SGEFA)}

\section{(i) Traditional GEFA}

The current study uses SGEFA (Yu et al. 2017a,b; Wang et al. 2017), which is a refinement of the traditional GEFA technique (Liu et al. 2008; Liu and Wen 2008), to isolate the feedback of terrestrial vegetation to the regional climate of LPB. SGEFA is first validated by assessing the response of the South American climate to a well-studied forcing [El Niño-Southern Oscillation
(ENSO)], and later applied to study the vegetation feedbacks.

The traditional GEFA technique is based on the stochastic climate theory of Frankignoul and Hasselmann (1977). GEFA has the capability to isolate the impact of a slowly evolving boundary forcing on the rapidly evolving atmosphere, in the presence of other forcings. It was developed to isolate both local and nonlocal feedbacks, and can be used with observations as well as model output (Liu et al. 2008). While initially applied to SST forcing (Wen et al. 2010; Zhong et al. 2011; Wang et al. 2013), GEFA has been successfully employed to isolate the feedback of vegetation indices on the atmosphere across North America (Wang et al. 2014). The vegetation feedbacks extracted using GEFA and SGEFA have been successfully validated against dynamical assessments across North America using the National Center for Atmospheric Research Community Climate System Model 3.5 (Wang et al. 2014), and across North Africa using the Community Earth System Model (Yu et al. 2017a).

The atmosphere at any time instant $t$ is subject to variations due to its "rapid" internal variability and the "slow" boundary forcings from SSTs or vegetation cover. At time scales greater than or equal to a month, the change in the atmospheric variable can be decomposed into two terms as follows (Frankignoul et al. 1998; Liu et al. 2008):

$$
\mathbf{A}(t)=\mathbf{B} \times \mathbf{Y}(t)+\mathbf{N}(t),
$$

where $\mathbf{A}(t)$ represents the atmospheric variable at time $t$, $\mathbf{B}$ is the feedback matrix that we want to compute, $\mathbf{Y}(t)$ is a matrix of slowly evolving forcings, and $\mathbf{N}(t)$ is the atmospheric internal noise. Multiplying $\mathbf{Y}^{\mathrm{T}}(t-\tau)$ on both sides and expressing the terms as covariance yields

$$
\mathbf{C}_{\mathrm{AY}}(\tau)=\mathrm{BC}_{\mathrm{YY}}(\tau)+\mathbf{C}_{\mathrm{NY}}(\tau) .
$$

The superscript $\mathrm{T}$ represents the transpose, $\tau$ represents the lag time, and $\mathbf{C}$ is a covariance matrix between variables denoted by its subscript. Equation (2) states that the response of the atmosphere to slow-process forcings (e.g., SSTs, NDVI, etc.) at a lag time of $\tau$ is a sum of the response of the so-called slow and rapid components to the same lagged forcings. The longest memory of the internal variability component is 1 week (i.e., rapid) (Frankignoul and Hasselmann 1977). Additionally, the internal variability of a future time cannot force oceanic or land surface variability at an earlier point in time. Thus, the covariance of $\mathbf{Y}(t-\tau)$ with $\mathbf{N}(t)$ is assumed to be zero. The feedback matrix $\mathbf{B}$ can then be computed as 


$$
\mathbf{B}=\mathbf{C}_{\mathbf{A Y}}(\tau) \mathbf{C}_{\mathbf{Y Y}}(\tau)^{-1}
$$

The finite sample size of observed data can lead to significant sampling error as the lag increases because of the declining autocovariance term $\mathbf{C}_{\mathbf{Y Y}}(\tau)$. Therefore, the computation of $\mathbf{B}$ is restricted to the first lag (i.e., $\tau=1$ month only) (Wang et al. 2014). Each vector of the feedback matrix $\mathbf{B}$ represents the response of the atmospheric variable $\mathbf{A}$ to a corresponding slowly varying forcing in the matrix $\mathbf{Y}$. The units of $\mathbf{B}$ are the units of the atmospheric variable per the units of vegetation indices or of SST. The feedback strength, which can be quantified by multiplying $\mathbf{B}$ by the standard deviation of the corresponding forcing (e.g., SST, vegetation greenness), will be referred to as the "response pattern" of the atmospheric variable to the corresponding forcing.

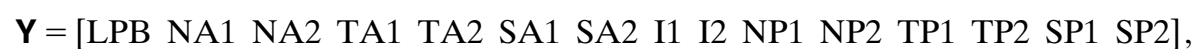

where LPB, 1 , and 2 represent the PCs of the LPB vegetation and the first and the second dominant mode of SST EOFs, respectively. Finally, the seasonal feedback is computed as the average of the feedback strength from the individual calendar months.

\section{(ii) Stepwise selection}

The short length of available observed datasets and the large number of forcings can generate substantial sampling errors in the GEFA analysis (Wang et al. 2017). The stepwise GEFA (Yu et al. 2017a) was developed to reduce this error by identifying a suitable subset of the full forcing matrix, by dropping the relatively less important forcings. An automatic selection routine using a forward selection approach (Hocking 1976) was employed to achieve the subset selection. We followed a similar methodology prescribed by Wang et al. (2017) and Yu et al. (2017a,b) to build a statistical prediction model. The relative performance of the models at every step of the forward selection is quantified using the Akaike information criterion (AIC; Akaike 1974). First, for the system with $N$ forcings, the vegetation forcing is fixed as the only component of the forcing matrix, and the GEFA feedback is calculated. The AIC of this model ( $\left.\mathrm{AIC}_{1}\right)$ is computed. Second, keeping the vegetation forcing fixed in the forcing matrix, we use AIC to identify the best two-forcing model, that is, the two-forcing model with the lowest AIC (or $\mathrm{AIC}_{2}$ ). In the third step, $\mathrm{AIC}_{2}$ is compared with $\mathrm{AIC}_{1}$. If $\mathrm{AIC}_{2}$ is less than $\mathrm{AIC}_{1}$, then the two-forcing model is preferred. The same steps are repeated while adding one forcing at a time until no further addition is warranted
We perform this analysis in a truncated EOF space, using only the first few dominant modes of the forcing variables. For the oceanic forcing, the global ocean north of $60^{\circ} \mathrm{S}$ is divided into seven nonoverlapping basins. EOF analysis is performed to extract the leading two modes from each basin. The vegetation forcing is extracted by applying EOF analysis to the VI datasets over the LPB and validating against the MOD6 dataset. The choice of a mode of variability as the vegetation forcing for this analysis was done on the basis of the explained variability as well as coherence among the different datasets. MOD6 was thus employed due to known issues with the longer-term datasets (e.g., errors induced due to multisensor nature of the dataset, AVHRR sensor degradation, etc.). All 15 forcings were compiled into a single forcing matrix $\mathbf{Y}$ : by the AIC approach (i.e., until the minimum AIC of higher-order models is greater than the AIC of the lower-order model). This procedure is performed to generate the set of most important forcings for each grid cell in the atmospheric field. The first element of the feedback vector thus generated at each grid cell gives the feedback coefficient of the vegetation forcing.

The statistical significance of the SGEFA response pattern is estimated using the Monte Carlo bootstrap approach (Czaja and Frankignoul 2002; Wang et al. 2014, 2017; Yu et al. 2017a). In this approach, the atmospheric variable at every location is scrambled randomly in time and the corresponding SGEFA feedback coefficients are calculated (this step is repeated 500 times to generate a sampling distribution). The original feedback is compared against the randomly generated feedback to assess the statistical significance.

\section{Results}

In the oceanic basins, the leading EOFs show naturally occurring dominant modes of SST variability. In our analysis, we extracted the two dominant modes of variability for the seven oceanic subbasins and the leading mode of variability for the LPB vegetation indices. The PCs of these 15 modes represent the local and remote forcings.

\section{a. Oceanic and terrestrial forcings}

\section{1) OCEANIC FORCINGS}

We highlight 4 of the 14 oceanic modes extracted using EOF analysis. These modes represent oceanic spatial 
(a)

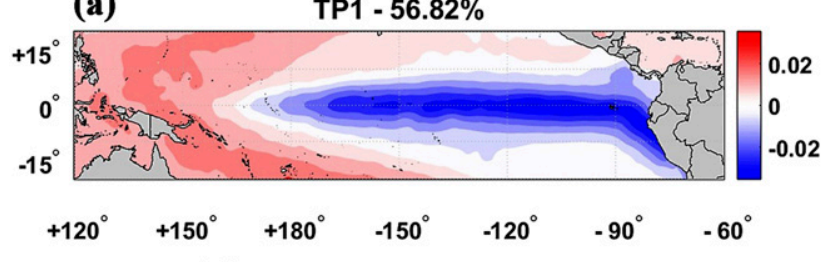

(c) TA1 $-42.60 \%$

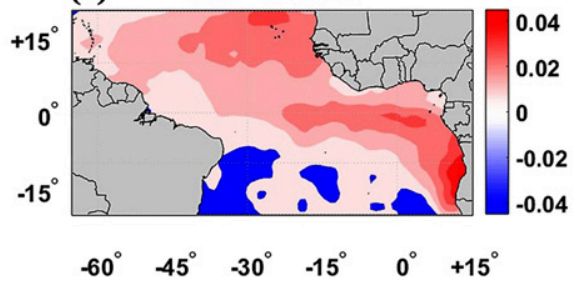

(e)

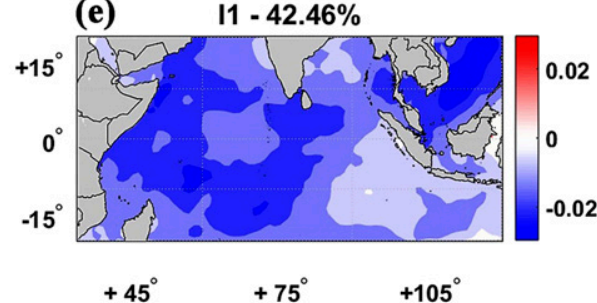

(g)

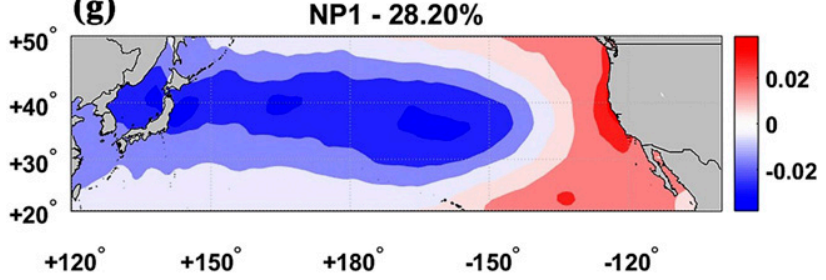

(b) PC - TP1 (ENSO)

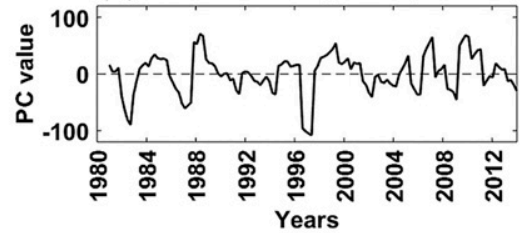

(d) PC - TA1 (Atlantic Niño)

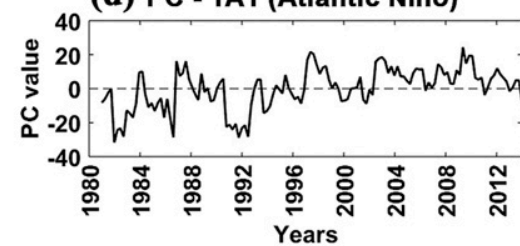

(f) PC - I1 (IO monopole)
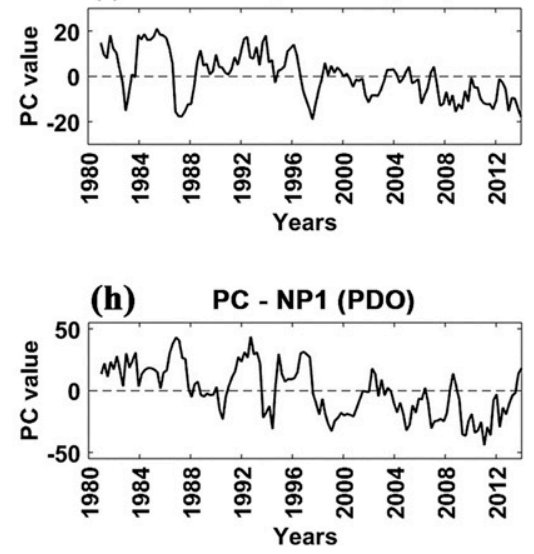

FIG. 2. Observed (left) EOF1 $\left({ }^{\circ} \mathrm{C}\right.$ ) and (right) PC1 (unitless) of monthly (a),(b) tropical Pacific, (c),(d) tropical Atlantic, (e),(f) Indian Ocean, and (g),(h) North Pacific SSTs for the ASON season.

patterns that have been previously identified in the literature, and have a pronounced effect on the general circulation. Figure 2 shows the dominant SST EOFs of the tropical Pacific Ocean (TP1), tropical Atlantic Ocean (TA1), Indian Ocean (I1), and North Pacific Ocean (NP1), and their corresponding PCs for the ASON season during the period 1981-2014. TP1 (Fig. 2a) represents the cold phase of the ENSO mode-a La Niña pattern with the characteristic cold tongue feature in the central and eastern tropical Pacific (Philander 1990) explaining $56.82 \%$ of the TP SST variability. The corresponding PC series correlates significantly with the Oceanic Niño Index $(r=-0.935, p \sim 0$; not shown here). Its pronounced effect on the global circulation is well documented. TA1 (Fig. 2b) is similar to the cold phase of tropical Atlantic Niño mode (Merle 1980; Zebiak 1993; Chang et al. 2006), explaining $42.60 \%$ of the TA SST variability. Apart from being a moisture source for LPB wet season precipitation (Martinez and Dominguez 2014), many studies have indicated that the tropical Atlantic has strong influence on the precipitation of tropical South America through interannual SST variability (Moura and Shukla 1981; Hastenrath 1984; Nobre and Shukla 1991). Seager et al. (2010) showed the importance of both tropical Pacific and tropical Atlantic SSTs in driving precipitation variability across LPB, on both interannual and longer time scales. The dominant mode of the tropical Indian Ocean (I1; Fig. 2c) represents the warm phase of Indian Ocean basin mode (Klein et al. 1999; Xie et al. 2002) while explaining $42.46 \%$ of the tropical Indian Ocean variability. The dominant mode in the North Pacific Ocean (NP1) represents the warm phase of the Pacific decadal oscillation (PDO) mode (Zhang et al. 1997; Mantua et al. 1997), explaining $28.20 \%$ of the NP SST variability, and the corresponding PC series is significantly correlated with the PDO index ( $r=0.935, p \sim 0$; not shown here).

\section{2) TERRESTRIAL FORCING}

Past studies have successfully used GEFA to isolate the land surface feedback from that of oceanic forcings 

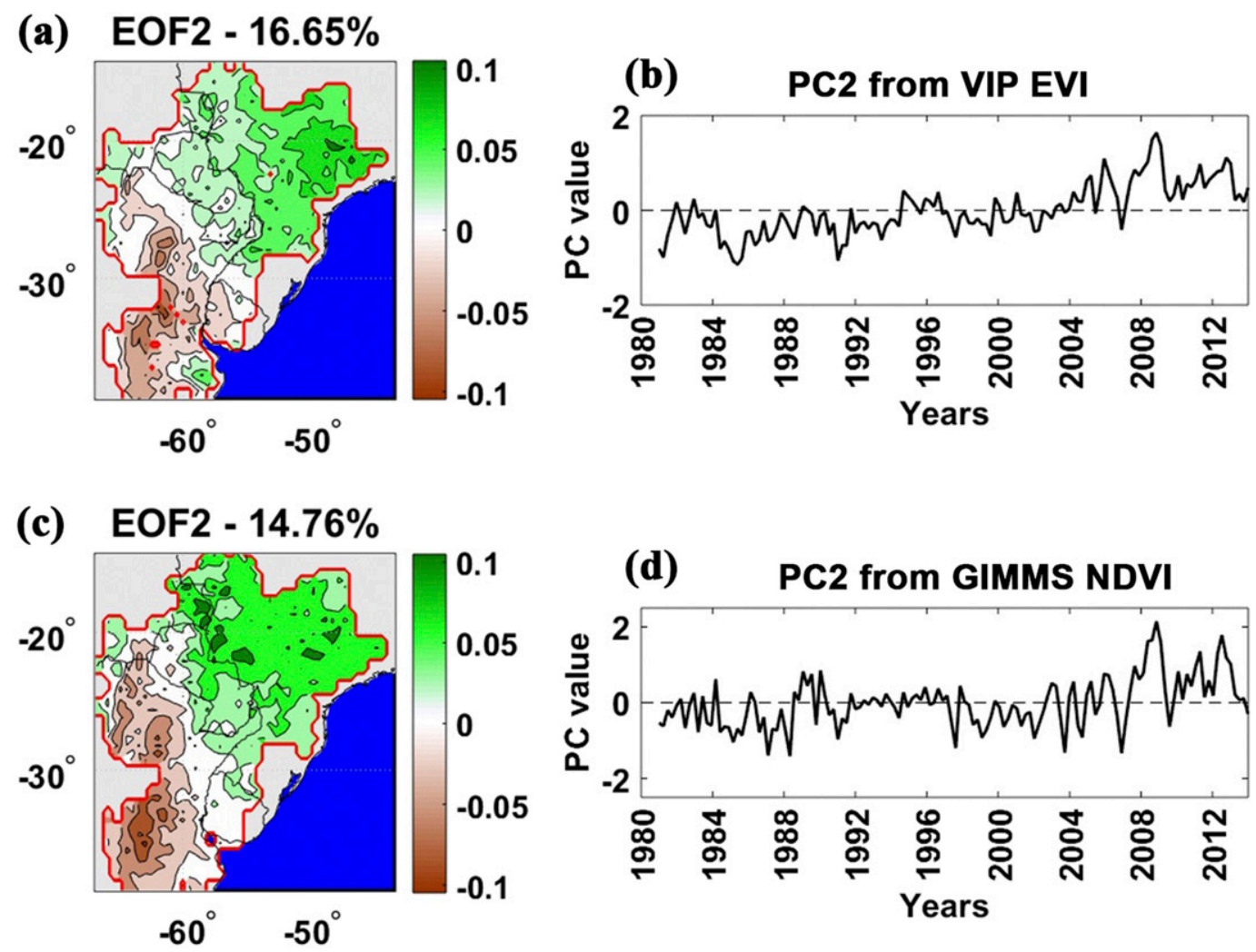

FIG. 3. Observed (left) EOF2 (units of VI) and (right) PC2 (unitless) of monthly (a),(b) VIP EVI, and (c),(d) GIMMS NDVI respectively for ASON season over LPB. PC time series in (b) and (d) are significantly correlated with linear correlation value $=0.79(p$ value $\sim 0)$.

(Wang et al. 2014). These studies use time series of spatially averaged NDVI as the terrestrial forcing in the GEFA forcing matrix. However, the hydroclimatic response of LPB to sub-basin-scale land cover changes varies depending on the region (Lee and Berbery 2012). For this reason, this analysis uses sub-basin-scale patterns of variability (EOF modes).

We performed the EOF analysis using the monthly vegetation indices from the long-term datasets (VIP EVI and GIMMS NDVI) for the ASON season during 1981-2014. The identification of a long-term vegetation forcing was made carefully due to the multisensor nature of the datasets, known issues with the AVHRR reflectance data prior to 2000 , and the difficulty in interpretation of EOFs since physical modes do not always have to follow the orthogonality constraint (Hannachi et al. 2007). To evaluate the robustness of the modes of the long-term datasets, we repeated the EOF analysis using the shorter MOD6 EVI (2000-17) as a benchmark (Fig. S1 in the online supplemental material). The first dominant mode of long-term VIP EVI dataset (Fig. S2) shows basinwide greening explaining $27.95 \%$ of the vegetation index variability. However, this mode does not correspond to any of the first five dominant modes from MOD6 EVI data that together explain $51.40 \%$ of the variability. We suspect that the first dominant vegetation mode is capturing the variability related to the sensors, and not related to vegetation variability. For this reason, we do not choose this mode as the vegetation forcing.

The second dominant mode from the VIP EVI2 and GIMMS NDVI datasets (Fig. 3) and the dominant mode of the MOD6 EVI data depict a basinwide dipole of vegetation index anomalies, with greening (positive VI anomalies) to the north/northeast and browning (negative VI anomalies) to the south and west. This dipole mode accounts for $16.65 \%, 14.76 \%$, and $15.06 \%$ of the VI variability in the VIP EVI, GIMMS NDVI, and MOD6 EVI data, respectively. The northeast-southwest aligned pattern suggests a differential response of the two parts of the basin to the forcings that shape vegetation variability in the years when this mode is active (characterized by high positive and low negative PC values). This mode is hereinafter referred to as the LPB vegetation dipole. The spatial structure of both the positive and the negative VI anomalies is consistent 
among all three datasets for the dipole mode. The detrended PC series of this dipole mode from the three datasets are positively correlated $(r$ value between MOD6 EVI and VIP EVI is 0.96; between MOD6 EVI and GIMMS NDVI is 0.85 ) significant at the $95 \%$ confidence interval in the overlapping years of 2000-14 (see Fig. S1b). In the analysis that follows, the PC time series were detrended to remove any long-term signals, thus isolating the interannual variability, which is the focus of the analysis. None of the higher-order modes were considered because the contribution to explained variability falls sharply to less than 5\% after the second mode.

We further analyze the dominant vegetation pattern to investigate the possible first-order controls on the observed sub-basin-scale vegetation index variability. The LPB was divided into two nonoverlapping partsnorth (NLPB; $\left.14^{\circ}-26^{\circ} \mathrm{S}, 43^{\circ}-60^{\circ} \mathrm{W}\right)$ and south (SLPB; $\left.26^{\circ}-38^{\circ} \mathrm{S}, 57^{\circ}-67^{\circ} \mathrm{W}\right)$ - thus encompassing the strongest positive and negative vegetation index anomalies. The division along $26^{\circ} \mathrm{S}$ is conveniently based on MODIS global land cover data (Channan et al. 2014; Friedl et al. 2010) such that NLPB mainly covers savannas/woody savannas and croplands, along with deciduous broadleaf forest toward the central LPB region, whereas SLPB primarily contains croplands and grasslands. Figure 4 shows the lagged correlation led by precipitation (from the UDEL dataset), between spatial average vegetation index anomalies for the month of September and spatial mean of monthly precipitation anomalies for the period 1981-2014 for NLPB and SLPB. Vegetation in NLPB responds positively and at short time scales (significant positive correlation coefficients for lag times of $0-2$ months) to changes in precipitation. This suggests a rapid response of vegetation variability to precipitation forcing. Vegetation in SLPB is strongly and significantly correlated with precipitation at the end of previous wet season. The peak of the correlation curve appears at a lag of 5 months (April), significant at the $95 \%$ confidence interval. Similar curves for all other months of the ASON season show similar behavior.

\section{b. Tropical Pacific feedback}

We analyzed the SGEFA results of one oceanic forcing (tropical Pacific) for the SON season. Assessment of the atmospheric response to SST variability over the tropical Pacific serves as a demonstration of SGEFA's ability to isolate the well-studied atmospheric response of this region to tropical Pacific SST forcing, in the presence of additional forcings. As shown in the EOF analysis, ENSO is the dominant mode of tropical Pacific SSTs and the forcing (TP1) represents La Niña (Fig. 1a). The large-scale SGEFA response to TP1 is assessed over each atmospheric grid point in the domain

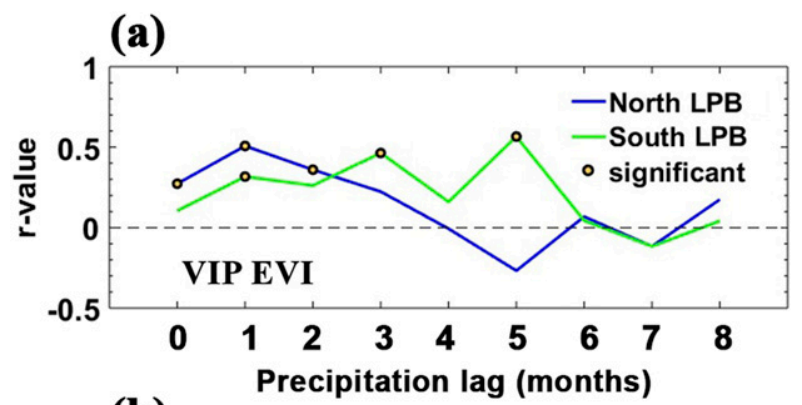

(b)

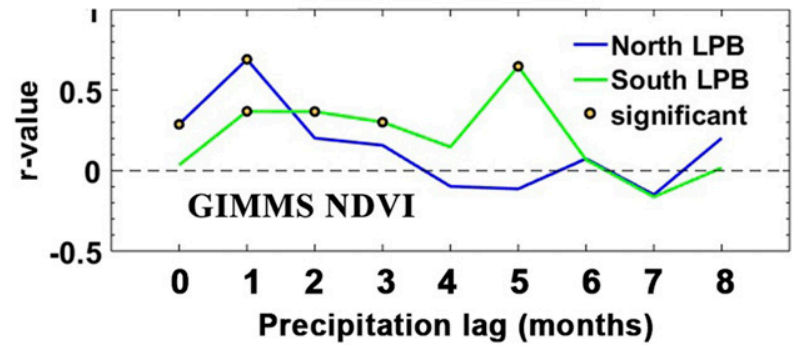

FIG. 4. Lagged correlation between spatial mean of vegetation index anomalies for the month of September and spatial mean of monthly UDEL precipitation anomalies for the period 1981-2014 (precipitation leads the vegetation index) for north LPB $\left(14^{\circ}-26^{\circ} \mathrm{S}\right.$, $\left.43^{\circ}-60^{\circ} \mathrm{W}\right)$ and south LPB $\left(26^{\circ}-38^{\circ} \mathrm{S}, 57^{\circ}-67^{\circ} \mathrm{W}\right)$, using (a) VIP EVI and (b) the GIMMS NDVI dataset. The axis labels indicate the lag (in months). For example, a lag of 0 refers to the vegetation index and precipitation anomalies of the same month (i.e., September), whereas a lag of 1 refers to the correlation between vegetation index anomalies of September and precipitation anomalies of previous August, and so on. Circular markers denote correlation values significant at the $95 \%$ confidence interval. Note the differential behavior of north LPB and south LPB, and the consistent behavior between the two datasets.

$160^{\circ} \mathrm{W}-40^{\circ} \mathrm{E}, 15^{\circ} \mathrm{N}-60^{\circ} \mathrm{S}$, while terrestrial air temperature and terrestrial precipitation are analyzed over the continent. The feedback matrices (units: atmospheric variable per unit forcing variable) have been multiplied by the standard deviation of the forcing time series (units: forcing variable) to quantify the feedback strength, that is, the response pattern represents anomalies (units: atmospheric variable) in the respective variable as an isolated response to one standard deviation $\mathrm{PC}$ of the forcing mode.

Figure 5 shows the SGEFA response of geopotential heights and winds at $250 \mathrm{hPa}$, heights at $850 \mathrm{hPa}$, VIMF, terrestrial air temperature, and precipitation to a $\mathrm{La}$ Niña forcing. The upper-air response shows negative pressure anomalies across the tropical Pacific with the strongest cyclonic wind anomalies off the western coast of subtropical South America, opposing the flow of the climatological subtropical jet stream. Because of the enhanced subsidence over the central Pacific during La Niña conditions, the Hadley circulation can no longer 

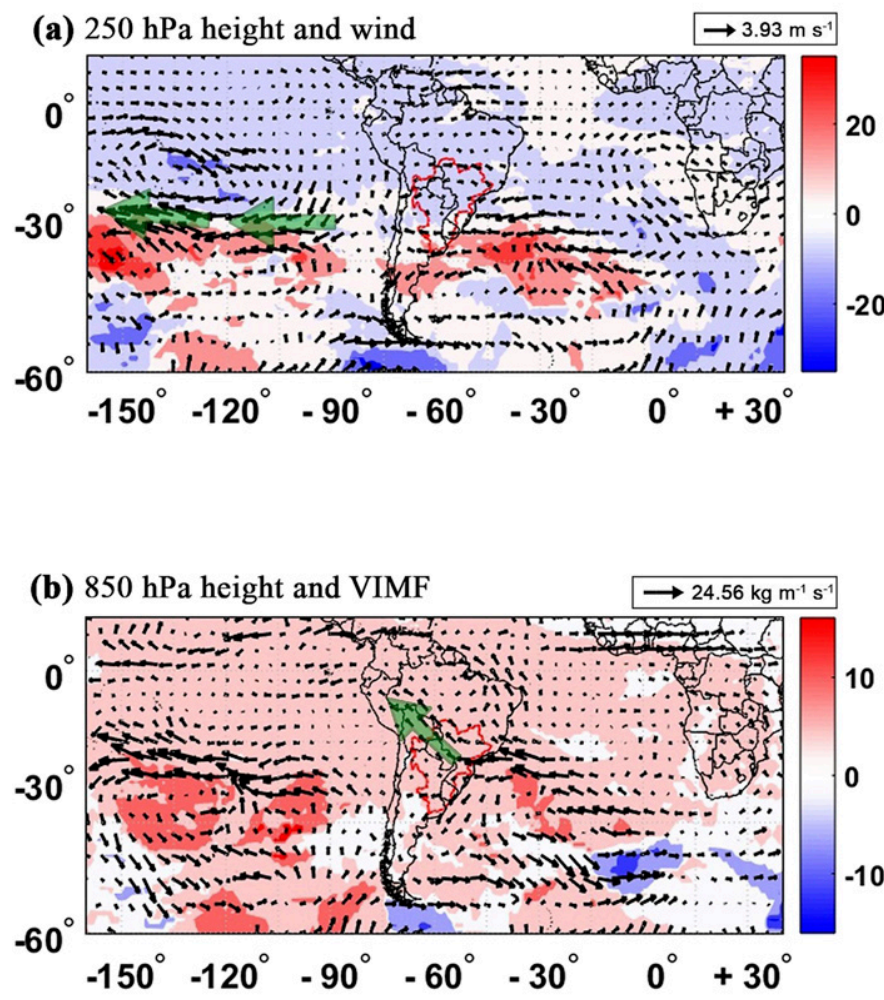

(c) Terrestrial air temperature

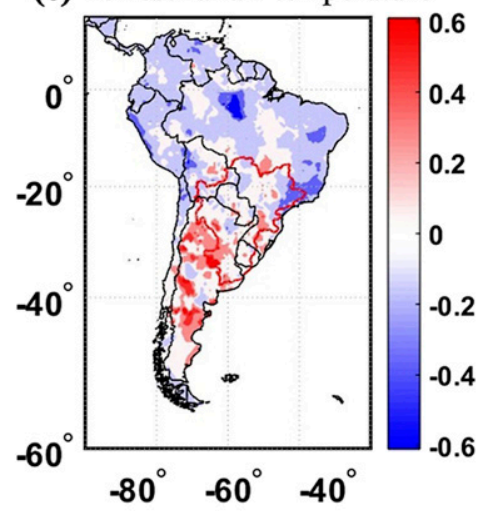

(d) Precipitation

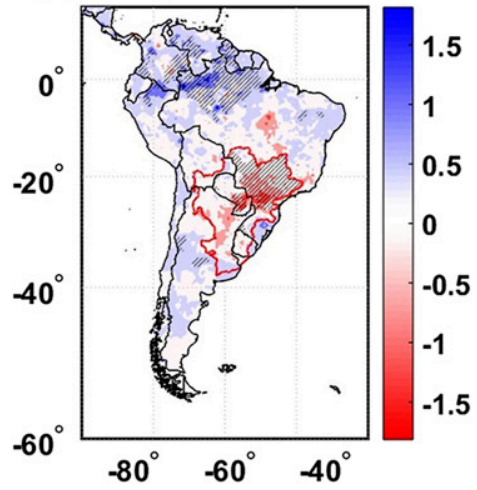

FIG. 5. Observed SGEFA response pattern of (a) geopotential height (m) and wind $\left(\mathrm{m} \mathrm{s}^{-1}\right)$ at $250 \mathrm{hPa}$, (b) geopotential height $(\mathrm{m})$ at $850 \mathrm{hPa}$ and vertical integral of moisture flux $\left(\mathrm{kg} \mathrm{m}^{-1} \mathrm{~s}^{-1}\right)$ from the ERA-Interim dataset, (c) terrestrial air temperature $\left({ }^{\circ} \mathrm{C}\right)$, and (d) precipitation $\left(\mathrm{mm} \mathrm{day}^{-1}\right)$ from the University of Delaware dataset, to La Niña forcing during SON. Additional green arrows (not to scale) depict the large-scale anomalies of wind and VIMF in (a) and (b), respectively. Black shading (hatching) indicates statistical significance at the $90 \%$ confidence level using a Monte Carlo bootstrap approach with 500 iterations.

maintain a strong subtropical jet stream, as evident in the strong easterly anomalies in the Pacific at the climatological position of the jet (centered around $30^{\circ} \mathrm{S}$ ) indicating a weakening of the westerly jet. Strong negative height anomalies are present south of the continent, extending into the Bellingshausen Sea region (between $60^{\circ}$ and $90^{\circ} \mathrm{W}$, south of $60^{\circ} \mathrm{S}$ ). The anomalous troughing south of South America evident in the 250$\mathrm{hPa}$ height response has been observed as a robust feature in all seasons during cold ENSO events by Kiladis and Mo (1998). This feature, along with increased heights over midlatitudes, marks the poleward shift of the polar jet stream due to La Niña. Corresponding shifts in the frequency of cyclones due to this shift in the position of storm tracks related to ENSO have been found by Sinclair et al. (1997).

The lower atmosphere $(850 \mathrm{hPa})$ response to La Niña (Fig. 5b) over continental South America shows strong southeasterly anomalies of moisture flux over tropical and subtropical South America, with strongest anomalies centered around the tripoint between Bolivia, Brazil, and Paraguay. The pattern is collocated with the climatological position of the SALLJ and favors the weakening of the jet (Marengo et al. 2004). The SALLJ brings moisture-laden winds from the north into LPB. This reduced moisture flux into the region suggesting low-level divergence is in agreement with past studies (Ropelewski and Halpert 1987, 1989; Aceituno 1988; Grimm et al. 1998; Grimm 2003; Grimm and Ambrizzi 2009). Previous studies also suggest that the enhanced subsidence associated with the descending branch of the Hadley cell leads to clear skies, enabling more shortwave radiation to reach the surface, thereby increasing the net radiation absorbed by the surface. This is reflected in the north-south dipole in temperature over continental South America as captured by SGEFA (Fig. 5c). Figure 5d shows the SGEFA response of precipitation over LPB due to a La Niña forcing. Results 
show a basinwide reduction in precipitation over LPB and enhanced precipitation over tropical Amazonia, significant at the $90 \%$ level. In conclusion, this technique recovers the classical atmosphere response of the South American continent to La Niña, which is characterized by tropics-tropics and tropics-extratropics teleconnections.

\section{c. Feedback response due to vegetation changes in the La Plata River basin}

\section{1) OBSERVED RESPONSE}

As shown in the EOF analysis, the terrestrial forcing represents a dipole anomaly in vegetation index characterized by greening over northeast LPB and browning of the south and west LPB. In this section, we analyze how the different atmospheric variables respond to this dominant mode of terrestrial forcing.

Figure 6 shows the SGEFA response of different atmospheric variables focused over LPB to highlight important regional responses. Figure 6a suggests an increase in the evapotranspiration (and consequently the latent heat flux) in the broad area dominated by positive vegetation index anomalies (greening). There is an indication of decreased latent heat flux in the southern and western parts of the basin. Additional analysis of total evaporation feedback using the GLEAM dataset also confirms similar finding (Fig. S4). Figure 6b exhibits an east-west-oriented dipole in the sensible heat flux response with a strong center of significant positive anomalies in the west, and a decrease in the broad area dominated by greening. This response is dependent not only on the dominant vegetation forcing but also on the underlying land cover. The western part of LPB is covered by savanna to the north and grassland/cropland to the south (Fig. 1). The increase in sensible heat flux is collocated with the browning of this region where water availability is limited (Lee and Berbery 2012). The temperature response shows an increase in surface air temperature over western and southern LPB with the highest anomalies of $0.55^{\circ} \mathrm{C}$, and cooler temperatures in the northeast LPB, consistent with the response of surface heat fluxes. Similar results from the GIMMS NDVI dataset (Fig. S5) show a statistically significant dipole response with warming over southwestern LPB and cooling over northeastern LPB. An interesting feature is the increase in temperature over northern Argentina encompassing the region dominated by the NAL. The subsequent changes in Bowen ratio are reflected in the boundary layer depth response (Fig. 6d) with significant positive anomalies toward the west, positive anomalies in central LPB along the dipole axis of vegetation dipole mode (the boundary between positive and negative VI anomalies), and negative anomalies outside the basin (north, northeast, and southeast).
Figure 6e shows a basinwide dipole of surface pressure response with a consistent orientation and sign with the vegetation dipole mode. The positive surface pressure anomaly in the northern and eastern parts of the domain, and reduced surface pressure over the south LPB, west LPB, and the region dominated by the NAL, support anomalous circulation to the east of the browning region. Past studies have concluded that a deepening of the NAL leads to an acceleration of the northerly flow across LPB and changes in the intensity and position of precipitation (Seluchi et al. 2003; Ferreira et al. 2006). The moisture flux anomalies (Fig. 6e) maintain a northerly direction over central LPB, indicating the increased southward penetration of moisture into LPB. The easterly enhancement of moisture flux over southern LPB can increase the transport of oceanic moisture into LPB, and/or can play a role in preventing the tropical moisture flux from exiting the LPB from a northern latitude, thus supporting a deeper penetration of moisture across the basin.

Figure $6 f$ shows the SGEFA response of LPB precipitation to the dipole mode from VIP EVI dataset. The response of precipitation shows statistically significant increase over central and south LPB with magnitudes ranging from 0.5 to $1.2 \mathrm{~mm} \mathrm{day}^{-1}$ as an isolated response to the vegetation dipole. Results from GIMMS NDVI dataset (Fig. S5) are consistent in terms of the spatial pattern and magnitude of the response. The magnitude of the vegetation-forced response is roughly half of the magnitude of ENSO-forced response. Results from traditional GEFA for a larger domain around South America (Figs. S5 and S6) support the current findings.

\section{2) Proposed MECHANISM}

The greening up of vegetation in north/northeast LPB (positive vegetation index anomalies) results in increased latent heat flux (Fig. 6a), enhanced evaporation/ transpiration (Fig. S4) and increase in local moisture availability. The observed increase in latent heat flux is accompanied by decrease in sensible heat flux (Fig. 6b), leading to a reduction in the Bowen ratio. The consequent evaporative cooling and decreased sensible heat flux decreases the near-surface air temperature in the greening region (Fig. 6c) and leads to an increase in surface pressure (Fig. 6e).

The browning of savannas, grasslands, and croplands in western and southern LPB has profound effects on the energy budget at the surface. The observed increase in sensible heat flux is consistent with the increase in surface air temperature and leads to an increase in the depth of the daytime boundary layer (Fig. 6). The net column heating leads to a warming of the boundary layer and reduction in surface pressure. The VIMF 
(a) Surface latent heat flux

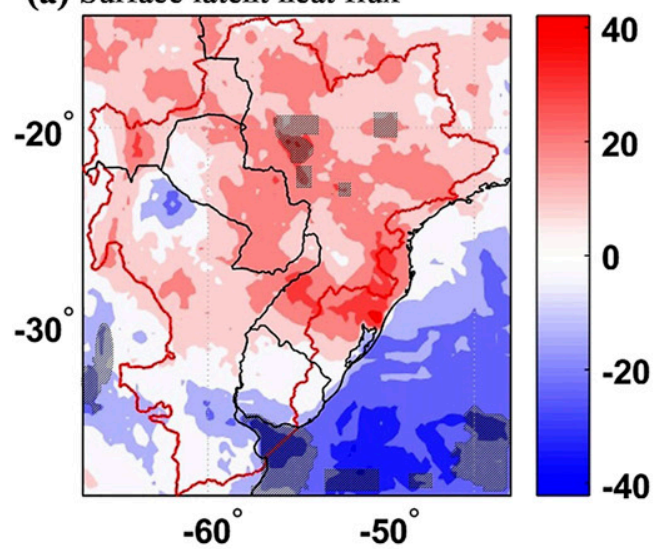

(b) Surface sensible heat flux

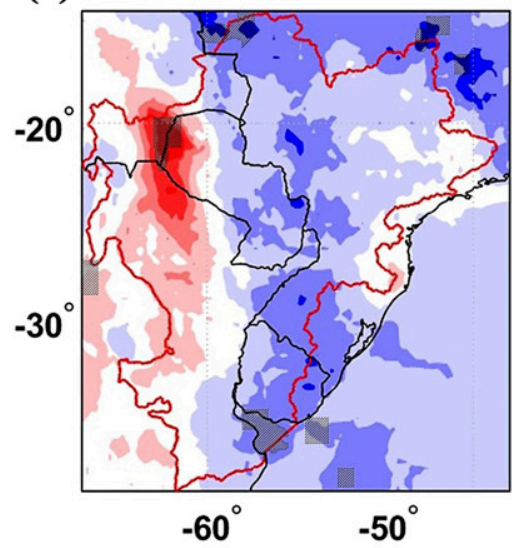

(c) Terrestrial air temperature
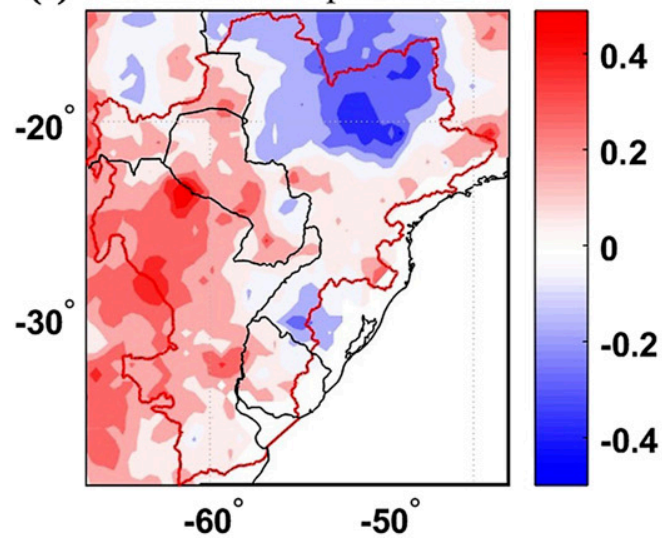

(d) Daytime boundary layer depth
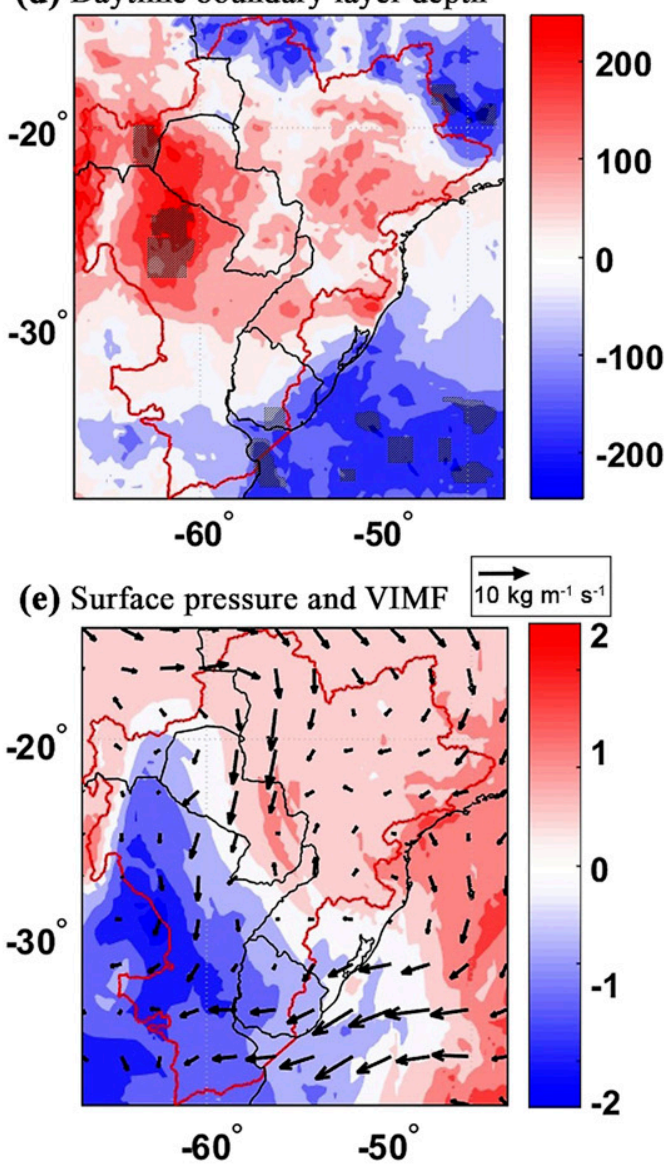

(f) Precipitation

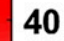

20

0

$-20$

$-40$

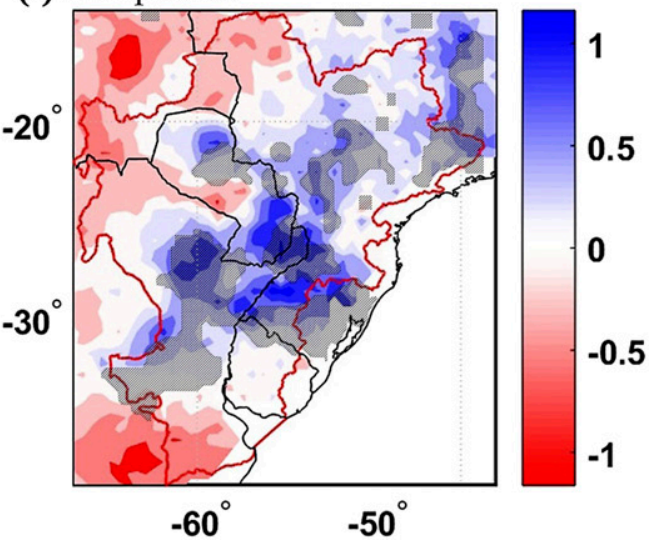

FIG. 6. Observed SGEFA response pattern of (a) surface latent heat flux $\left(\mathrm{W} \mathrm{m}^{-2}\right)$, (b) surface sensible heat flux $\left(\mathrm{W} \mathrm{m}^{-2}\right),(\mathrm{c})$ terrestrial air temperature $\left({ }^{\circ} \mathrm{C}\right),(\mathrm{d})$ boundary layer depth $(\mathrm{m}),(\mathrm{e})$ surface pressure $(\mathrm{hPa})$ and VIMF $\left(\mathrm{kg} \mathrm{m}^{-1} \mathrm{~s}^{-1}\right)$, and (f) precipitation $\left(\mathrm{mm} \mathrm{day}^{-1}\right)$ to LPB vegetation forcing during SON. Atmospheric data derived from ERA-Interim reanalysis for (a), (b), (d), and (e), and from the University of Delaware dataset for (c) and (f). Black shading (hatching) indicates statistical significance at the $90 \%$ confidence level using a Monte Carlo bootstrap approach with 500 iterations. 
anomaly response (i.e., increased northerly transport of moisture, and convergence into the broad region dominated by the browning) is coherent with a geostrophic response to a deepened thermal low. The land surface forcing thus leads to a modulation of the large-scale circulation, while reinforcing the NAL system. The enhanced moisture can potentially come from all three (or more) sources-the tropical Amazon, subtropical Atlantic, and advection of increased evapotranspiration from NLPB (local recycling) - and needs to be examined in future work.

The sub-basin-scale changes in the land surface of LPB result in increased moisture transport into central and south La Plata. Additionally, the existing climatological convective instability (Zipser et al. 2006; Salio et al. 2007) is conditioned by increased sensible heat flux, thus providing a positive feedback to precipitation over the region, as an isolated response to the vegetation dipole (Fig. 6f). Weather Research and Forecasting (WRF) Model analyses done by Ferreira et al. (2006) also suggest that deepening of the NAL by drier surface conditions led to a southward shift in the precipitation systems and anomalous intensification of the rain over SLPB.

\section{Conclusions and discussion}

The current study isolates the impact of interannual variability in vegetation indices on the climate of LPB, using multiple observational datasets analyzed in a multivariate statistical framework: the stepwise GEFA (or SGEFA). We present an observational analysis of the local and remote feedback of LPB vegetation on South American seasonal climate at a regional scale. This work uses observations to build on past understanding of land-atmosphere interactions over LPB that has mainly come from numerical modeling studies (e.g., Dirmeyer and Brubaker 2007; Lee and Berbery 2012; Sörensson and Menéndez 2011; Zemp et al. 2014; Martinez and Dominguez 2014; Sörensson and Berbery 2015; Ruscica et al. 2015; Spennemann and Saulo 2015; Spennemann et al. 2018, which includes remotely sensed observations as well; etc.)

The assessment of vegetation feedback using observations is particularly challenging because the response of the atmosphere to vegetation is modest as compared to atmospheric internal variability, making it difficult to isolate. The presence of other forcings such as oceanic SSTs greatly influences the response. The short length of available datasets poses yet another limitation. While past studies have assessed this response in a numerical modeling framework, this is a first attempt at understanding the local and remote influence of vegetation variability on the LPB climate using observations. The identification of the vegetation forcing is accomplished using multiple satellite datasets. The SGEFA framework is first validated against the well-studied response to the ENSO forcing. The results, compared to past studies, clearly show the capability of this technique to isolate the response signal in the presence of other forcings.

Reanalysis data have been employed because they provide the best available spatially and temporally consistent estimates of near-surface variables needed to evaluate these physical mechanisms, in a region with sparse measurements. It is important to note, however, that the ERA-Interim reanalysis dataset is produced using a land surface model that does not include the interannual variability of vegetation properties. Because our proposed mechanism relies on vegetation variability, this can affect our results. However, we rely on the sequential data assimilation capability of ERA-Interim to constrain model estimates close to observed data, and the skill and accuracy of the forecast model to retain the assimilated information.

It should be kept in mind that the current results are based on a linearity assumption of the GEFA and SGEFA statistical framework. In the real world, however, vegetation feedbacks can be nonlinear (Zeng et al. 2002; Zhou et al. 2003; Wang et al. 2014). Higher-order effects, lag times greater than 1 month, and the feedbacks during other seasons have not been explored yet. The accuracy of this analysis is also limited by the errors in observations, and the short length of available data for a statistical analysis. Wang et al. (2014) showed that GEFA results using 25-yr data contain large sampling errors.

The dominant vegetation forcing, extracted using EOF analysis, consists of a dipole of vegetation index anomalies with greening to the northeast and browning to the southwest of the LPB. SGEFA applied to extract the isolated response of LPB climate to the vegetation forcing, revealed the role of the induced dipole of nearsurface atmospheric pressure in setting up cross-basin circulations that increase the transport of moisture to the east of the region dominated by browning. The proposed mechanism has been summarized in Fig. 7. The greening up of northeast LPB leads to an increase in evapotranspiration, cooling, and increased surface pressure locally. The browning over savannas and croplands/ grasslands in southwestern LPB leads to the increase in sensible heat flux, warmer temperatures, and decrease in surface pressure. The geostrophic response to this induced pressure gradient leads to anomalous northerly enhancement of moisture-laden winds, deeper penetration of moisture into LPB, and increased precipitation over central and southern parts of the basin. The sign and 


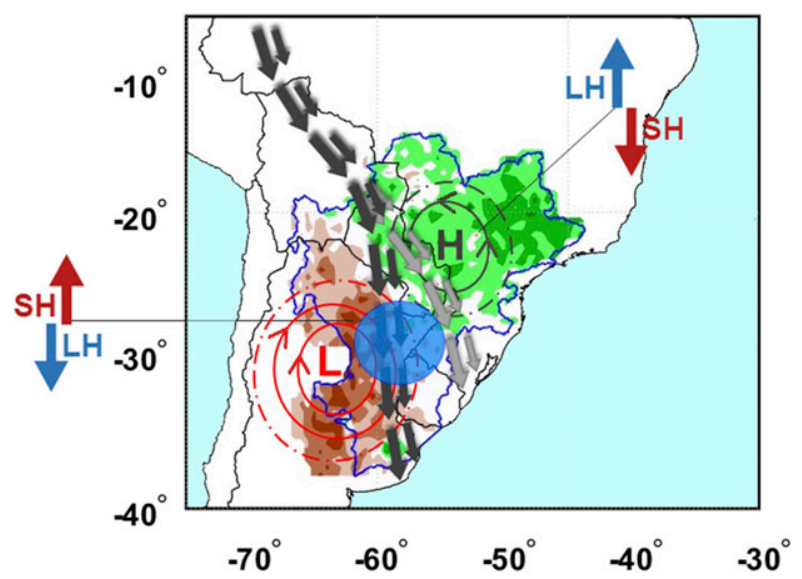

FIG. 7. Schematic depicting the impact of the vegetation dipole mode (EOF2) on the seasonal climate of LPB, overlaid on the vegetation dipole pattern. $\mathrm{SH}$ and $\mathrm{LH}$ indicate response of surface sensible and latent heat fluxes, respectively; red and blue arrows indicate the sign of this anomalous response. Letters $\mathrm{H}$ and $\mathrm{L}$ show the regions of anomalous high and low surface pressure, respectively. Gray and black arrows show the meridionally enhanced and southward shifted SALLJ trajectory (black arrows) from its climatological mean position (gray arrows). The blue circle indicates the region of enhanced precipitation.

pattern of anomalous precipitation are consistent with the findings of Saulo et al. (2010), who evaluated the impact of changes in soil moisture in subtropical Argentina on precipitation and low-level circulation during a NAL event. There results also indicate a modulation of the overlying circulation at synoptic spatial and temporal scales by changes on the land surface, such that a northerly enhancement of moisture flux leads to a southward displacement of the exit region of the jet and increased precipitation over LPB centered around $30^{\circ} \mathrm{S}$. The impact on seasonal precipitation is of great importance for the region, as precipitation fuels hydroelectricity, which along with rain-fed agriculture forms the backbone of the economy of the five countries within the LPB.

Using SGEFA in "free selection" mode allows us to evaluate the ranking of the most important slow-varying forcings for the region (see Fig. S7 for more details). The most important SON forcings (in descending order) are EOF1 and EOF2 of the tropical Pacific, EOF2 of the Indian Ocean, EOF2 of the South Pacific, and the LPB vegetation dipole. Notably, the land surface forcing is deemed as the most important SGEFA forcing for October precipitation (Fig. S7b).

Future work would need to address the relevance of other modes of vegetation variability, other seasons, higher-order SST modes, and the impact of other potentially important forcings (e.g., Amazon vegetation). More importantly, assessing the relative impacts of moisture recycling and thermodynamic/dynamic landatmosphere feedbacks on modulation of LPB climate, and assessing the relative importance of different moisture sources. This observational framework is limited by the availability of long-term accurate datasets. These results should be regarded as a first-order evidence of the existing link between land surface variability and seasonal climate. This understanding is potentially valuable for seasonal prediction as a spring dipole in vegetation with greening in the north and browning in the south would indicate increased probability of precipitation for the following month. In our future work using numerical simulations, we will investigate the hypothesis that recycling is the likely mechanism for the observed changes. Understanding the effects of vegetation variability and change is particularly important in this region because the basins of La Plata and the Amazon have faced some of the highest deforestation rates in the world (Coronel et al. 2002; Nepstad et al. 2009; Hansen et al. 2013). In the Argentinian part of LPB, agricultural intensification and extensification have dominated the trends of land use change (Coutinho et al. 2009). It is therefore critical to better understand the effect of the land surface on the climate of the most heavily populated and economically active region of South America, where improved hydroclimate understanding is essential for the prosperity of its 67 million inhabitants.

Acknowledgments. This work is supported by National Science Foundation Grant 1454089. We thank Dr. Michael Notaro and Dr. Yan Yu for insightful discussion on the SGEFA technique. We are grateful to Dr. Notaro and one anonymous reviewer for valuable feedback. The MODIS VI products were retrieved from the online EARTHDATA tool (https://earthdata.nasa.gov/), courtesy of the NASA EOSDIS Land Processes Distributed Active Archive Center (LP DAAC), and MODIS land cover type dataset from Global Land Cover Facility (GLCF). The authors declare no competing financial interests.

\section{REFERENCES}

Aceituno, P., 1988: On the functioning of the Southern Oscillation in the South America sector. Part I: Surface climate. Mon. Wea. Rev., 116, 505-524, https://doi.org/10.1175/15200493(1988)116<0505:OTFOTS >2.0.CO;2.

Akaike, H., 1974: A new look at the statistical model identification. IEEE Trans. Automat. Contr., 19, 716-723, https://doi.org/ 10.1109/TAC.1974.1100705.

Barros, V., R. Clarke, and P. Silva Días, Eds., 2006: Climate Change in La Plata Basin. CIMA/CONICET-UBA.

Bonan, G. B., 1997: Effects of land use on the climate of the United States. Climatic Change, 37, 449-486, https://doi.org/10.1023/ A:1005305708775. 
_- 2002: Ecological Climatology: Concepts and Applications. Cambridge University Press, 678 pp.

Bounoua, L. E., G. J. Collatz, S. O. Los, P. J. Sellers, D. A. Dazlich, C. J. Tucker, and D. A.Randall, 2000: Sensitivity of climate to changes in NDVI. J. Climate, 13, 2277-2292, https://doi.org/ 10.1175/1520-0442(2000)013<2277:SOCTCI >2.0.CO;2.

Bretherton, C. S., C. Smith, and J. M. Wallace, 1992: An intercomparison of methods for finding coupled patterns in climate data. J. Climate, 5, 541-560, https://doi.org/10.1175/ 1520-0442(1992)005<0541:AIOMFF >2.0.CO;2.

Budyko, M. I., 1974: Climate and Life. Academic Press, 507 pp.

Caffera, R. M., and E. H. Berbery, 2002: La Plata basin climatology. Climate Change in the La Plata Basin. Inter-American Institute on Global Change, 16-34.

Chang, P., and Coauthors, 2006: Climate fluctuations of tropical coupled systems-The role of ocean dynamics. J. Climate, $\mathbf{1 9}$, 5122-5174, https://doi.org/10.1175/JCLI3903.1.

Channan, S., K. Collins, and W. R. Emanuel, 2014: Global mosaics of the standard MODIS land cover type data. University of Maryland and the Pacific Northwest National Laboratory, accessed 25 September 2018.

Coronel, G., A. Menendez, and L. Chamorro, 2002: Physiography and hydrology. Climate Change in the La Plata Basin. InterAmerican Institute on Global Change, 44-59.

Coutinho, H. L., E. Noellemeyer, E. Jobbagy, M. Jonathan, and J. M. Paruelo, 2009: Impacts of land use change on ecosystems and society in the Rio de La Plata Basin. Applying Ecological Knowledge to Landuse Decisions, H. Tiessen and J. W. Stewart, Eds., IAI Publications, xxxx.

Czaja, A., and C. Frankignoul, 2002: Observed impact of Atlantic SST anomalies on the North Atlantic Oscillation. J. Climate, 15, 606-623, https://doi.org/10.1175/1520-0442(2002)015<0606: OIOASA $>2.0 . \mathrm{CO} ; 2$.

Dee, D. P., and Coauthors, 2011: The ERA-Interim reanalysis: Configuration and performance of the data assimilation system. Quart. J. Roy. Meteor. Soc., 137, 553-597, https://doi.org/ 10.1002/qj.828.

Dickinson, R. E., and A. Henderson-Sellers, 1988: Modeling tropical deforestation: A study of GCM land-surface parametrizations. Quart. J. Roy. Meteor. Soc., 114, 439-462, https:// doi.org/10.1002/qj.49711448009.

Didan, K., 2015: MOD13Q1 MODIS/Terra Vegetation Indices 16-Day L3 Global $250 \mathrm{~m}$ SIN Grid V006 [Data set]. NASA EOSDIS LP DAAC, accessed 29 March 2018, https://doi.org/ 10.5067/MODIS/MOD13Q1.006.

__ , and A. Barreto, 2016: NASA MEaSUREs Vegetation Index and Phenology (VIP) Vegetation Indices Monthly Global 0.05 Deg CMG [Data set]. NASA EOSDIS Land Processes DAAC, accessed 19 August 2016, https://doi.org/10.5067/ MEaSUREs/VIP/VIP30.004.

Dirmeyer, P. A., and K. L. Brubaker, 2007: Characterization of the global hydrologic cycle from a back-trajectory analysis of atmospheric water vapor. J. Hydrometeor., 8, 20-37, https:// doi.org/10.1175/JHM557.1.

FAO, 2016: AQUASTAT website: Food and Agriculture Organization of the United Nations (FAO). Accessed 12 May 2018, http://www.fao.org/nr/water/aquastat/basins/la-plata/ index.stm.

Ferreira, L. J., C. Saulo, R. Juan, and M. Seluchi, 2006: The impact of land use changes over the low level circulation related to the northwestern Argentinean Low. Proc. Eighth Int. Conf. on Southern Hemisphere Meteorology and Oceanography (ICSHMO), Foz do Iguaçu, Brazil, INPE, 1029-1035.
Flinker, R., 2012: La Plata River Basin. 4 pp., http://citeseerx. ist.psu.edu/viewdoc/download;jsessionid =E9A1F3A20A 99EDC060552157EDA17921? doi=10.1.1.706.502\& rep $=$ rep1\&type $=$ pdf

Frankignoul, C., and K. Hasselmann, 1977: Stochastic climate models. Part II: Application to sea-surface temperature anomalies and thermocline variability. Tellus, 29, 289-305, https://doi.org/10.3402/tellusa.v29i4.11362.

— A. Czaja, and B. L'Heveder, 1998: Air-sea feedback in the North Atlantic and surface boundary conditions for ocean models. J. Climate, 11, 2310-2324, https://doi.org/10.1175/ 1520-0442(1998)011<2310:ASFITN > 2.0.CO;2.

Friedl, M. A., D. Sulla-Menashe, B. Tan, A. Schneider, N. Ramankutty, A. Sibley, and X. Huang, 2010: MODIS Collection 5 global land cover: Algorithm refinements and characterization of new datasets, 2001-2012. Remote Sens. Environ., 114, 168-182, https://doi.org/10.1016/j.rse.2009.08.016.

Fukuoka, A., 1951: A study of 10-day forecast (a synthetic report). Geophys. Mag., 12, 177-218.

Granger, C. W., 1969: Investigating causal relations by econometric models and cross-spectral models. Econometrica, 37, 424-438, https://doi.org/10.2307/1912791.

Grimm, A. M., 2003: The El Niño impact on the summer monsoon in Brazil: Regional processes versus remote influence. J. Climate, 16, 263-280, https://doi.org/10.1175/1520-0442(2003)016<0263: TENIOT $>2.0 . \mathrm{CO} ; 2$.

- and T. Ambrizzi, 2009: Teleconnections into South America from the tropics and extratropics on interannual and intraseasonal timescales. Past Climate Variability in South America and Surrounding Regions, Developments in Paleoenvironmental Research, F. Vimeux, F. Sylvestre, and M. Khodri, Eds., Springer, 159-191.

— S. E. Ferraz, and J. Gomes, 1998: Precipitation anomalies in Southern Brazil associated with El Niño and La Niña events. J. Climate, 11, 2863-2880, https://doi.org/10.1175/15200442(1998)011<2863:PAISBA > 2.0.CO;2.

Guillod, B. P., and Coauthors, 2015: Reconciling spatial and temporal soil moisture effects on afternoon rainfall. Nat. Commun., 6, 6443, https://doi.org/10.1038/ncomms7443.

Guo, Z., and Coauthors, 2006: GLACE: The Global LandAtmosphere Coupling Experiment. 2. Analysis. J. Hydrometeor., 7, 611-625, https://doi.org/10.1175/JHM511.1.

Hannachi, A., I. T. Jolliffe, and D. B. Stephenson, 2007: Empirical orthogonal functions and related techniques in atmospheric science: A review. Int. J. Climatol., 27, 1119-1152, https:// doi.org/10.1002/joc.1499.

Hansen, M. C., and Coauthors, 2013: High-resolution global maps of 21st-century forest cover change. Science, 342, 850-853, https://doi.org/10.1126/science.1244693.

Hastenrath, S., 1984: Interannual variability and annual cycle: Mechanisms of circulation and climate in the tropical Atlantic. Mon. Wea. Rev., 112, 1097-1107, https://doi.org/10.1175/15200493(1984)112<1097:IVAACM > 2.0.CO;2.

Hocking, R. R., 1976: The analysis and selection of variables in linear regression. Biometrics, 32, 1-49, https://doi.org/10.2307/ 2529336.

Huete, A., K. Didan, T. Miura, E. P. Rodriguez, X. Gao, and L. G. Ferreira, 2002: Overview of the radiometric and biophysical performance of the MODIS vegetation indices. Remote Sens. Environ., 83, 195-213, https://doi.org/10.1016/S00344257(02)00096-2.

Jiang, Z., A. R. Huete, K. Didan, and T. Miura, 2008: Development of a two-band enhanced vegetation index without a blue 
band. Remote Sens. Environ., 112, 3833-3845, https://doi.org/ 10.1016/j.rse.2008.06.006.

Kiladis, G. N., and K. C. Mo, 1998: Interannual and intraseasonal variability in the Southern Hemisphere. Meteorology of the Southern Hemisphere, Meteor. Monogr., Vol. 49, Amer. Meteor. Soc., 307-336.

Klein, S. A., B. J. Soden, and N.-C. Lau, 1999: Remote sea surface temperature variations during ENSO: Evidence for a tropical atmospheric bridge. J. Climate, 12, 917-932, https://doi.org/10.1175/1520-0442(1999)012<0917: RSSTVD $>2.0 . \mathrm{CO} ; 2$.

Knist, S., and Coauthors, 2016: Land-atmosphere coupling in EURO-CORDEX evaluation experiments. J. Geophys. Res., 122, 79-103, https://doi.org/10.1002/2016JD025476.

Koster, R. D., and Coauthors, 2004: Regions of strong coupling between soil moisture and precipitation. Science, 305, 11381140, https://doi.org/10.1126/science.1100217.

— , and Coauthors, 2006: GLACE: The Global Land-Atmosphere Coupling Experiment. 1. Overview and results. J. Hydrometeor., 7, 590-610, https://doi.org/10.1175/JHM510.1.

Kutzbach, J. E., 1967: Empirical eigenvectors of sea-level pressure, surface temperature. J. Appl. Meteor., 6, 791-802, https://doi.org/ 10.1175/1520-0450(1967)006<0791:EEOSLP > 2.0.CO;2.

Lee, S.-J., and E. H. Berbery, 2012: Land cover change effects on the climate of the La Plata basin. J. Hydrometeor., 13, 84-102, https://doi.org/10.1175/JHM-D-11-021.1.

Liebmann, B., G. Kiladis, C. Vera, C. Saulo, and L. Carvalho, 2004: Subseasonal variations of rainfall in South America in the vicinity of the low-level jet east of the Andes and comparison to those in the South Atlantic convergence zone.J. Climate, 17, 3829-3842, https://doi.org/10.1175/1520-0442(2004)017<3829: SVORIS $>2.0 . C O ; 2$.

Liu, Z., and N. Wen, 2008: On the assessment of nonlocal climate feedback. Part I: The generalized equilibrium feedback assessment. J. Climate, 21, 134-148, https://doi.org/10.1175/ 2007JCLI1826.1.

,-- , and Y. Liu, 2008: On the assessment of nonlocal climate feedback. Part I: The generalized equilibrium feedback assessment. J. Climate, 21, 134-148, https://doi.org/10.1175/ 2007JCLI1826.1.

Lorenz, E. N., 1956: Empirical orthogonal functions and statistical weather prediction. Department of Meteorology, MIT, Statistical Forecast Project Rep. 1, 98 pp.

Mantua, N. J., S. R. Hare, Y. Zhang, J. M. Wallace, and R. C. Francis, 1997: A Pacific interdecadal climate oscillation with impacts on salmon production. Bull. Amer. Meteor. Soc., 78, 1069-1080, https://doi.org/10.1175/1520-0477(1997)078<1069: APICOW $>2.0 . \mathrm{CO} ; 2$.

Marengo, J. A., W. R. Soares, C. Saulo, and M. Nicolini, 2004: Climatology of the low-level jet east of the Andes as derived from the NCEP-NCAR reanalyses: Characteristics and temporal variability. J. Climate, 17, 2261-2280, https://doi.org/ 10.1175/1520-0442(2004)017<2261:COTLJE >2.0.CO;2.

_ and Coauthors, 2012: Recent developments on the South American monsoon system. Int. J. Climatol., 32, 1-21, https:// doi.org/10.1002/joc.2254.

Martens, B., and Coauthors, 2017: GLEAM v3: Satellite-based land evaporation and root-zone soil moisture. Geosci. Model Dev., 10, 1903-1925, https://doi.org/10.5194/gmd-101903-2017.

Martinez, J. A., and F. Dominguez, 2014: Sources of atmospheric moisture for the La Plata river basin. J. Climate, 27, 6737-6753, https://doi.org/10.1175/JCLI-D-14-00022.1.
Merle, J., 1980: Variabilité thermique annuelle et interannuelle de l'océan Atlantique équatorial Est. L'hypothèse d'un "El Niño" Atlantique. Oceanol. Acta, 3, 209-220.

Miralles, D. G., T. R. Holmes, R. A. de Jeu, J. Gash, A. G. Meesters, and A. J. Dolman, 2011: Global land-surface evaporation estimated from satellite-based observations. $H y$ drol. Earth Syst. Sci., 15, 453-469, https://doi.org/10.5194/hess15-453-2011.

Mitchell, T. D., and P. D. Jones, 2005: An improved method of constructing a database of monthly climate observations and associated high-resolution grids. Int. J. Climatol., 25, 693-712, https://doi.org/10.1002/joc.1181.

Moura, A. D., and J. Shukla, 1981: On the dynamics of droughts in northeast Brazil: Observations, theory and numerical experiments with a general circulation model. J. Atmos. Sci., $\mathbf{3 8}$, 2653-2675, https://doi.org/10.1175/1520-0469(1981)038<2653: OTDODI $>2.0 . \mathrm{CO} ; 2$.

Nemani, R. R., C. D. Keeling, H. Hashimoto, W. M. Jolly, S. C. Piper, C. J. Tucker, R. B. Myneni, and S. W. Running, 2003: Climate-driven increases in global terrestrial net primary production from 1982 to 1999 . Science, 300, 1560-1563, https:// doi.org/10.1126/science.1082750.

Nepstad, D., and Coauthors, 2009: The end of deforestation in the Brazilian Amazon. Science, 326, 1350-1351, https://doi.org/ 10.1126/science.1182108.

Nicolini, M., A. C. Saulo, J. C. Torres, and P. Salio, 2002: Enhanced precipitation over southeastern South America related to strong low-level jet events characterization during austral warm season. Meteorologica, 27, 59-70.

Nobre, P., and J. Shukla, 1991: Interannual variability of SST and wind stress over the tropical Atlantic and rainfall over Amazon and Northeast Brasil. Fifth Conf. on Climate Variations. Denver, CO, Amer. Meteor. Soc., 472-475.

Nogués-Paegle, J., and K. C. Mo, 1997: Alternating wet and dry conditions over South America during summer. Mon. Wea. Rev., 125, 279-291, https://doi.org/10.1175/1520-0493(1997) $125<0279$ :AWADCO $>2.0 . \mathrm{CO} ; 2$.

Obukhov, A. M., 1947: Statistically homogeneous fields on a sphere. Uspethi Math. Nauk, 2, 196-198.

_ 1960: The statistically orthogonal expansion of empirical functions. Bull. Acad. Sci. USSR. Geophys. Series (English Transl.), 1, 288-291.

Philander, S. G., 1990: El Niño, La Niña, and the Southern Oscillation. Academic Press, 293 pp.

Pielke, R. A., R. Avissar, M. Raupach, A. J. Dolman, X. Zeng, and A. S. Denning, 1998: Interactions between the atmosphere and terrestrial ecosystems: Influence on weather and climate. Global Change Biol., 4, 461-475, https://doi.org/10.1046/ j.1365-2486.1998.t01-1-00176.x.

_ , and Coauthors, 2007: An overview of regional land-use and land-cover impacts on rainfall. Tellus, 59B, 587-601, https:// doi.org/10.1111/j.1600-0889.2007.00251.x.

Pinzon, J. E., M. E. Brown, and C. J. Tucker, 2005: Satellite time series correction of orbital drift artifacts using empirical mode decomposition. Hilbert-Huang Transform: Introduction and Applications, N. Huang, Ed., World Scientific, 167-186.

Preisendorfer, R. W., 1988: Principal Component Analysis in Meteorology and Oceanography. Elsevier, $425 \mathrm{pp}$.

Rasmusson, E. M., and K. C. Mo, 1996: Large-scale atmospheric moisture cycling as evaluated from NMC global analysis and forecast products. J. Climate, 9, 3276-3297, https://doi.org/ 10.1175/1520-0442(1996)009<3276:LSAMCA >2.0.CO;2. 
Rayner, N. A., D. E. Parker, E. B. Horton, C. K. Folland, L. V. Alexander, D. P. Rowell, E. C. Kent, and A. Kaplan, 2003: Global analyses of sea surface temperature, sea ice, and night marine air temperature since the late nineteenth century. J. Geophys. Res., 108, 4407, https://doi.org/10.1029/ 2002JD002670.

Ropelewski, C. F., and M. S. Halpert, 1987: Global and regional scale precipitation patterns associated with the El Niño/Southern Oscillation. Mon. Wea. Rev., 115, 16061626, https://doi.org/10.1175/1520-0493(1987)115<1606: GARSPP $>2.0 . \mathrm{CO} ; 2$.

$\longrightarrow$, and 1989: Precipitation patterns associated with the high index phase of the Southern Oscillation. J. Climate, 2 , 268-284, https://doi.org/10.1175/1520-0442(1989)002<0268: PPAWTH $>2.0 . \mathrm{CO} ; 2$.

Running, S. W., and Coauthors, 1994: Terrestrial remote sensing science and algorithms planned for EOS/MODIS. Int. J. Remote Sens., 15, 3587-3620, https://doi.org/10.1080/ 01431169408954346.

Ruscica, R. C., A. A. Sörensson, and C. G. Menéndez, 2015: Pathways between soil moisture and precipitation in southeastern South America. Atmos. Sci. Lett., 16, 267-272, https:// doi.org/10.1002/asl2.552.

Salio, P., M. Nicolini, and C. Saulo, 2002: Chaco low-level jet events characterization during the austral summer season. J. Geophys. Res., 107, 4816, https://doi.org/10.1029/ 2001JD001315.

,-- , and E. J. Zipser, 2007: Mesoscale convective systems over southeastern South America and their relationship with the South American low-level jet. Mon. Wea. Rev., 135, 1290 1309, https://doi.org/10.1175/MWR3305.1.

Santanello, J. A., and Coauthors, 2018: Land-atmosphere interactions: The LoCo perspective. Bull. Amer. Meteor. Soc., 99, 1253-1272, https://doi.org/10.1175/BAMS-D-17-0001.1.

Saulo, C., L. Ferreira, J. Nogués-Paegle, M. Seluchi, and J. Ruiz, 2010: Land-atmosphere interactions during a northwestern Argentina low event. Mon. Wea. Rev., 138, 2481-2498, https:// doi.org/10.1175/2010MWR3227.1.

Seager, R., N. Naik, W. Baethgen, A. Robertson, Y. Kushnir, J. Nakamura, and S. Jurburg, 2010: Tropical oceanic causes of interannual to multidecadal precipitation variability in southeast South America over the past century. J. Climate, 23, 5517-5539, https://doi.org/10.1175/2010JCLI3578.1.

Seluchi, M., A. C. Saulo, M. Nicolini, and P. Satyamurty, 2003: The northwestern Argentinean low: A study of two typical events. Mon. Wea. Rev., 131, 2361-2378, https://doi.org/10.1175/ 1520-0493(2003)131<2361:TNALAS >2.0.CO;2.

Sinclair, M. R., J. A. Renwick, and J. W. Kidson, 1997: Lowfrequency variability of Southern Hemisphere sea level pressure and weather system activity. Mon. Wea. Rev., 125, 2531-2543, https://doi.org/10.1175/1520-0493(1997)125<2531: LFVOSH $>2.0 . \mathrm{CO} ; 2$.

Sörensson, A. A., and E. H. Berbery, 2015: A note on soil moisture memory and interactions with surface climate for different vegetation types in the La Plata basin. J. Hydrometeor., 16, 716-729, https://doi.org/10.1175/JHM-D-14-0102.1.

—_, and C. G. Menéndez, 2011: Summer soil-precipitation coupling in South America. Tellus, 63A, 56-68, https://doi.org/ 10.1111/j.1600-0870.2010.00468.x.

Spennemann, P. C., and A. C. Saulo, 2015: An estimation of the land-atmosphere coupling strength in South America using the Global Land Data Assimilation System. Int. J. Climatol., 35, 4151-4166, https://doi.org/10.1002/joc.4274.
, M. Salvia, R. C. Ruscica, A. A. Sörensson, F. Grings, and H. Karszenbaum, 2018: Land-atmosphere interaction patterns in southeastern South America using satellite products and climate models. Int. J. Appl. Earth Obs. Geoinf., 64, 96103, https://doi.org/10.1016/j.jag.2017.08.016.

Stohlgren, T. J., T. N. Chase, R. A. Pielke Sr., T. G. Kittel, and J. S. Baron, 1998: Evidence that local land use practices influence regional climate, vegetation, and stream flow patterns in adjacent natural areas. Global Change Policy, 4, 495-504, https:// doi.org/10.1046/j.1365-2486.1998.t01-1-00182.x.

Tucker, C. J., J. E. Pinzon, M. E. Brown, D. A. Slayback, E. W. Pak, R. Mahoney, E. F. Vermote, and N. El Saleous, 2005: An extended AVHRR 8-km NDVI dataset compatible with MODIS and SPOT vegetation NDVI data. Int. J. Remote Sens., 26, 4485-4498, https://doi.org/10.1080/ 01431160500168686.

Vera, C., and Coauthors, 2006: Toward a unified view of the American monsoon systems. J. Climate, 19, 4977-5000, https:// doi.org/10.1175/JCLI3896.1.

Wang, F., Z. Liu, and M. Notaro, 2013: Extracting the dominant SST modes impacting North America's observed climate. J. Climate, 26, 5434-5452, https://doi.org/10.1175/JCLI-D-1200583.1.

- M. Notaro, Z. Liu, and G. Chen, 2014: Observed local and remote influences of vegetation on the atmosphere across North America using a model-validated statistical technique that first excludes oceanic forcings. J. Climate, 27, 362-382, https://doi.org/10.1175/JCLI-D-13-00080.1.

-, Y. Yu, M. Notaro, J. Mao, X. Shi, and Y. Wei, 2017: Advancing a model-validated statistical method for decomposing the key oceanic drivers of regional climate: Focus on northern and tropical African climate variability in the Community Earth System Model (CESM). J. Climate, 30, 85178537, https://doi.org/10.1175/JCLI-D-17-0219.1.

Wen, N., Z. Liu, Q. Liu, and C. Frankignoul, 2010: Observed atmospheric responses to global SST variability modes: A unified assessment using GEFA. J. Climate, 23, 1739-1759, https://doi.org/10.1175/2009JCLI3027.1.

Willmott, C. J., and K. Matsuura, 1995: Smart interpolation of annually averaged air temperature in the United States. J. Appl. Meteor., 34, 2577-2586, https://doi.org/10.1175/15200450(1995)034<2577:SIOAAA > 2.0.CO;2.

Woodward, F. I., 1987: Climate and Plant Distribution. Cambridge University Press, $174 \mathrm{pp}$.

, M. R. Lomas, and C. K. Kelly, 2004: Global climate and the distribution of plant biomes. Philos. Trans. Roy. Soc. London, 359B, 1465-1476, https://doi.org/10.1098/rstb.2004.1525.

Xie, S.-P., H. Annamalai, F. A. Schott, and J. P. McCreary, 2002: Structure and mechanisms of south Indian Ocean climate variability. J. Climate, 15, 864-878, https://doi.org/10.1175/ 1520-0442(2002)015<0864:SAMOSI $>2.0$. CO;2.

Yu, Y., M. Notaro, F. Wang, J. Mao, X. Shi, and Y. Wei, 2017a: Validation of a statistical methodology for extracting vegetation feedbacks: Focus on North African ecosystems in the Community Earth System Model. J. Climate, 31, 1565-1586, https://doi.org/10.1175/JCLI-D-17-0220.1.

vegetation-rainfall feedbacks in the Sahel dominated by a moisture recycling mechanism. Nat. Commun., 8, 1873, https:// doi.org/10.1038/s41467-017-02021-1.

Zebiak, S. E., 1993: Air-sea interaction in the equatorial Atlantic region. J. Climate, 6, 1567-1586, https://doi.org/10.1175/15200442(1993)006<1567:AIITEA >2.0.CO;2. 
Zemp, D. C., C.-F. Schleussner, H. M. Barbosa, R. J. van der Ent, J. F. Donges, J. Heinke, G. Sampaio, and A. Rammig, 2014: On the importance of cascading moisture recycling in South America. Atmos. Chem. Phys., 14, 13337-13359, https:// doi.org/10.5194/acp-14-13337-2014.

Zeng, N., K. Hales, and J. D. Neelin, 2002: Nonlinear dynamics in a coupled vegetation-atmosphere system and implications for desert-forest gradient. J. Climate, 15, 34743487, https://doi.org/10.1175/1520-0442(2002)015<3474: NDIACV $>2.0 . C O ; 2$.

Zhang, Y., J. Wallace, and D. Battisti, 1997: ENSO-like interdecadal variability: 1900-93. J. Climate, 10, 1004-1020, https://doi.org/ 10.1175/1520-0442(1997)010<1004:ELIV>2.0.CO;2.
Zhong, Y. F., Z. Y. Liu, and M. Notaro, 2011: A GEFA assessment of observed global ocean influence on U.S. precipitation variability: Attribution to regional SST variability modes. J. Climate, 24, 693-707, https://doi.org/10.1175/2010JCLI3663.1.

Zhou, L., R. K. Kaufmann, Y. Tian, R. B. Myneni, and C. J. Tucker, 2003: Relation between interannual variations in satellite measures of northern forest greenness and climate between 1982 and 1999. J. Geophys. Res., 108, 4004, https://doi.org/ 10.1029/2002JD002510.

Zipser, E. J., D. J. Cecil, C. Liu, S. W. Nesbitt, and D. P. Yorty, 2006: Where are the most intense thunderstorms on Earth? Bull. Amer. Meteor. Soc., 87, 1057-1071, https://doi.org/ 10.1175/BAMS-87-8-1057. 